Research Article

\title{
Determination and Monitoring of Key Construction Control Indices for Low-Temperature Performance of Asphalt Mixtures Based on BIM Platform
}

\author{
Yulong Zhao $\mathbb{D}^{1,2}$ Ying Gao, ${ }^{2}$ Ke Zhang, ${ }^{3}$ Yao Zhang, ${ }^{4}$ and Mingce $\mathrm{Yu}^{5}$ \\ ${ }^{1}$ School of Civil Engineering, Shandong Jiaotong University, Jinan 250357, China \\ ${ }^{2}$ School of Transportation, Southeast University, Nanjing 211189, China \\ ${ }^{3}$ College of Information Engineering, Fuyang Normal University, Fuyang 236041, China \\ ${ }^{4}$ College of Civil Science and Engineering, Yangzhou University, Yangzhou 225127, China \\ ${ }^{5}$ School of Highway and Architecture, Shandong Transport Vocational College, Weifang 261206, China \\ Correspondence should be addressed to Yulong Zhao; zhylong15@yahoo.com
}

Received 27 October 2020; Revised 23 March 2021; Accepted 7 April 2021; Published 19 April 2021

Academic Editor: Paolo S. Valvo

Copyright (C) 2021 Yulong Zhao et al. This is an open access article distributed under the Creative Commons Attribution License, which permits unrestricted use, distribution, and reproduction in any medium, provided the original work is properly cited.

\begin{abstract}
The construction control indices were commonly used to ensure the quality of asphalt layers in the construction process. However, the relationship between the construction control indices and the low-temperature performance of asphalt layers is not clear. The purpose of this paper was to investigate the effect of the variations of the construction control indices on the low-temperature performance of asphalt mixtures to determine the key construction control indices, and propose the method for the monitoring of these indices using the Building Information Modeling (BIM) platform. The low-temperature performance of asphalt mixtures was evaluated by the semicircular bend (SCB) test. A new prediction model of critical strain energy release rate was established to evaluate the low-temperature performance of the asphalt layer. Five factors are considered for the low-temperature performance, which are the gradation and asphalt-aggregate ratio in the asphalt mixture plant, rolling temperature, gradation segregation, and temperature segregation. Orthogonal test (OT) results indicated that the order of importance of factors affecting the lowtemperature performance is asphalt-stone ratio, gradation, and molding temperature. The influences of gradation segregation and temperature segregation on the low-temperature performance were quantified in this study. Furthermore, the construction control indices were monitored by the BIM platform developed in this research. In the construction process of the asphalt layer, the gradation variation caused by the segregation should be paid more attention to ensure the low-temperature performance of the pavement.
\end{abstract}

\section{Introduction}

Low-temperature (transverse) cracking is one of the main distresses of asphalt pavement [1]. After the low-temperature cracks appear in the pavement, the main problem is that water will enter the pavement structure through the cracks. It will stay inside the pavement structure, weaken the strength of the base layer and the subgrade, accelerate the road damage, and reduce the driving quality $[2,3]$. Through investigation, it was found that the construction quality issue of asphalt layer is an important reason for the lowtemperature cracking of asphalt pavement $[4,5]$. The construction process control of the asphalt layers is mainly conducted according to the asphalt pavement construction specifications $[6,7]$. These specifications specify the items and frequency of quality inspection in the construction process, and give the requirements of the extreme value or range of the inspection items. However, these specifications do not clarify which construction control indices are related to a certain performance of the asphalt layer and the degree of influence, which causes blindness of construction.

The construction control indices mainly include the raw material properties, gradation of asphalt mixture, asphaltstone ratio, rolling temperature, rolling passes, degree of 
compaction, thickness of asphalt layer, and evenness [6, 7]. From the perspective of construction, the main factors affecting the construction quality can be summarized as the gradation of asphalt mixture, asphalt-stone ratio, rolling temperature, rolling passes, and thickness of the asphalt layer. Furthermore, under the same conditions, the volume parameters of the asphalt mixture are also determined by these factors.

There are many studies on various factors affecting the low-temperature performance of the asphalt mixture. $\mathrm{Li}$ et al. [8] analyzed the influence of different aging conditions on the low-temperature properties of asphalt mixtures. Dong et al. [9] studied the effects of traffic level, overlay thickness, mixture type, intensity of surface preparation before overlay, pavement thickness, and freeze index on transverse cracks based on the Long-Term Pavement Performance (LTPP) data. The National Cooperative Highway Research Program (NCHRP) report 9-22 [10] investigated the influencing factors of rutting, fatigue cracking, and lowtemperature cracking, including the factors related to construction process. However, the abovementioned influencing factors' analysis is not aimed at the construction of asphalt layers, and the range of the influencing factors is different from the actual construction of the asphalt layer. Moreover, these studies have not systematically and comprehensively compared the effects of the variations of different construction indices on the low-temperature performance of the asphalt layers. Therefore, it is necessary to investigate the relationship between the construction control indices and the low-temperature cracking of pavement to clarify the key construction indices of the lowtemperature performance.

After determining which indices need to be controlled, the following problem is how to achieve the real-time monitoring of the construction indices. In the asphalt mixture plant, the digital image processing technology $[11-14]$ or online detection $[6,7]$ was used to measure the gradation of asphalt mixture in real time. The asphalt content of the asphalt mixture can be measured in real time by the online detection of the asphalt mixture plant $[6,7]$. Moreover, the ground-penetrating radar can be used to determine the air voids and the thicknesses of the asphalt layers in real time [15].

After determining the real-time detection methods of the construction indices, it is also necessary to solve the monitoring problem of these construction indices. At present, the construction control of the asphalt layer is still conducted by the manual inspection and manual recording in China, which cannot meet the requirements of construction process control. Furthermore, these data are static and isolated, causing great inconvenience to road construction parties for monitoring, searching, and analyzing data. At the same time, paper documents are easy to lose and difficult to store. So, the intensity and timeliness of construction control decreased. In the field of building construction, Building Information Modeling (BIM) technology has been used to solve these problems [16-19]. Ding and Xu [20] established the BIM cloud storage system to solve a large number of problems such as data processing, information security, and cost in BIM model applications. Das et al. [21] put forward a web service framework for the integration and management of the construction supply chain data. Chen et al. [22] proposed a cloud-based framework that provides web-based services for viewing, storing, and analyzing BIM model data. Lin et al. [23] established a web-based BIM model process management system to improve the efficiency of contractors for sharing the construction information and tracking the construction project. Based on the natural languageprocessing method, Lin et al. [24] proposed an intelligent data retrieval method for cloud BIM applications, which is used to solve the contradiction between construction-related parties in finding the required information from a large amount of information. Sattineni and Azhar [25] integrated BIM models and Radio Frequency Identification (RFID) technology to monitor the construction personnel, equipment, and material status in real time. Conde et al. [26] investigated the advantages of the use of BIM with photogrammetry support in small projects. Most of the software is used for the modeling and designing of roads and bridges. Few BIM platforms can monitor the construction quality of roads and bridges in real time. Therefore, it is necessary to develop BIM platforms to display the construction information in real time.

The objective of this study was to investigate the effects of the variations of different construction indices on the lowtemperature performance of asphalt mixtures and give the monitoring method for these construction indices. Semicircular bend (SCB) test was used to evaluate the lowtemperature performance of asphalt mixtures. A new prediction model of critical strain energy release rate was proposed to evaluate the low-temperature performance of the asphalt layer. Moreover, the BIM platform was developed to monitor the construction quality of asphalt layer in real time.

\section{Experimental Program and BIM Platform}

The key construction control indices were determined using the laboratory tests, and the BIM platform was developed in this study, as shown in Figure 1.

2.1. Raw Materials. Styrene-butadiene-styrene (SBS) modified asphalt concrete-13 (AC-13) was selected as the research object in this study. The raw materials were provided by a highway construction project in China.

2.1.1. Asphalt. In this paper, the binder of SBS modified asphalt (I-C) was used. The basic performance can meet the requirements of JTG F40-2004 [6]. The results of performance tests according to JTG E20-2011 are shown in Table 1 [27].

2.1.2. Mineral Aggregate. In this study, four different kinds of crushed basalt aggregates were selected, which were 0-2.36 mm, 2.36-4.75 mm, 4.75-9.5 mm, and 9.5-13.2 mm, 


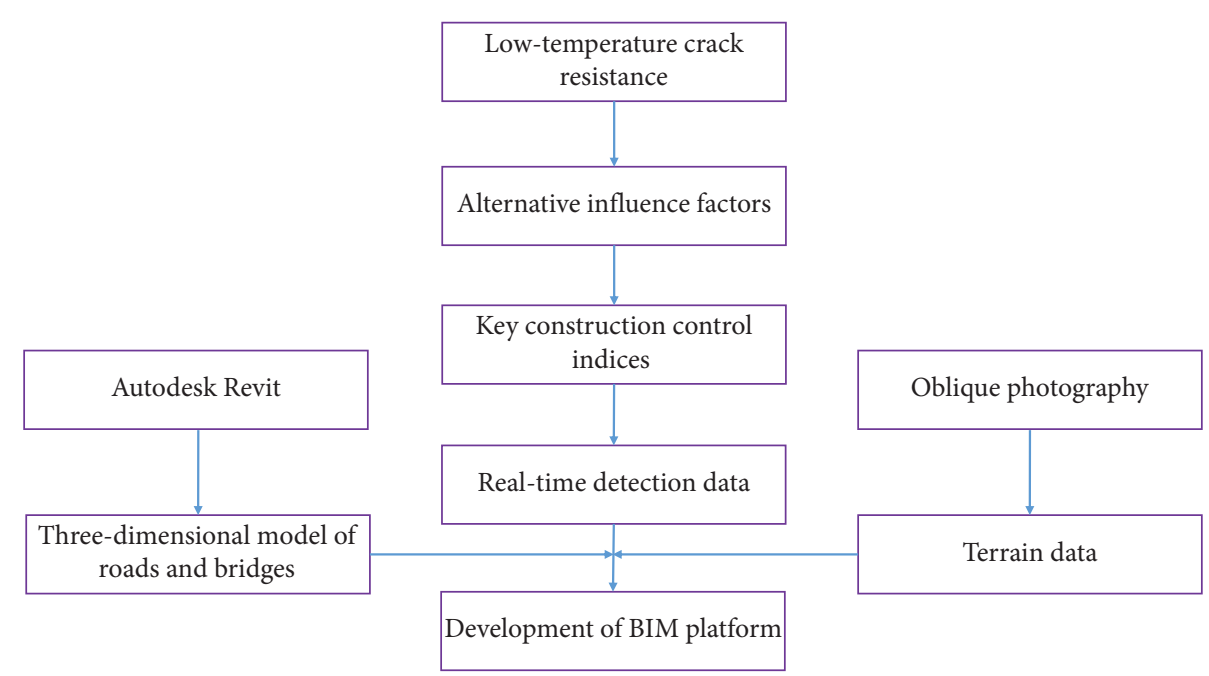

FIgURE 1: Technical route of this research.

TABle 1: Properties of SBS asphalt.

\begin{tabular}{|c|c|c|c|}
\hline Item & Tested result & Requirement & Test method \\
\hline Penetration $\left(25^{\circ} \mathrm{C}, 100 \mathrm{~g}, 5 \mathrm{~s}\right)(0.1 \mathrm{~mm})$ & 68 & $60 \sim 80$ & T 0604 \\
\hline Penetration index & 0.32 & $\geq-0.4$ & Т 0604 \\
\hline Ductility $\left(5^{\circ} \mathrm{C}, 5 \mathrm{~cm} / \mathrm{min}\right)(\mathrm{cm})$ & 44 & $\geq 30$ & T 0605 \\
\hline Softening point $\left({ }^{\circ} \mathrm{C}\right)$ & 77.9 & $\geq 55$ & T 0606 \\
\hline Kinematical viscosity $\left(135^{\circ} \mathrm{C}\right)(\mathrm{Pa} \cdot \mathrm{s})$ & 1.73 & $\leq 3$ & T 0625 \\
\hline Flashpoint $\left({ }^{\circ} \mathrm{C}\right)$ & 256 & $\geq 230$ & T 0611 \\
\hline Solubility in trichloroethylene (\%) & 99.64 & $\geq 99$ & T 0607 \\
\hline Elastic recovery $(\%)$ & 85.8 & $\geq 65$ & T 0662 \\
\hline Density $\left(25^{\circ} \mathrm{C}\right)\left(\mathrm{g} / \mathrm{cm}^{3}\right)$ & 1.023 & - & Т 0603 \\
\hline Storage stability $\left({ }^{\circ} \mathrm{C}\right)$ & 1.3 & $\leq 2.5$ & T 0661 \\
\hline \multirow{3}{*}{ Thin film oven test $\left(163^{\circ} \mathrm{C}\right)$} & -0.04919 & $-1.0-1.0$ & Т 0609 \\
\hline & 73.5 & $\geq 60$ & Т 0604 \\
\hline & 26.37 & $\geq 20$ & Т 0605 \\
\hline
\end{tabular}

respectively. The properties of these aggregates are shown in Table 2.

The properties of the limestone filler are presented in Table 3. The tests shown in Tables 2 and 3 were carried out according to JTG E42-2005 [28], and the requirements for these tests were determined based on JTG F40-2004 [6].

2.2. Mixture Design. To study the influence of construction control indexes on the low-temperature performance of the asphalt mixture, the mixture design should be done firstly. The gradation of AC-13 asphalt mixture is shown in Figure 2. The optimum asphalt-aggregate ratio (OAR) was determined by the Marshall Design method [6]. The molding temperature of specimens was $160^{\circ} \mathrm{C}$. The results of the mixture deign is presented in Table 4.

\subsection{Variability Design of Construction Control Indices}

2.3.1. Gradation, Asphalt-Aggregate Ratio, and Rolling Temperature. From the above analysis, the main factors affecting the construction quality are gradation, asphaltaggregate ratio, rolling temperature, rolling passes, and thickness of the asphalt layer. The number of rolling passes can be well controlled by using the Global Positioning System-Real Time Kinematic (GPS-RTK) technology [29]. The control of the thickness of the asphalt layer is relatively easy, for example, by manual detection [6]. Therefore, the mainly considered factors for the low-temperature performance of asphalt mixture in this research were gradation, asphalt-aggregate ratio, and rolling temperature of the asphalt mixture. In the plant of the asphalt mixture, the allowable range of gradation fluctuation for asphalt mixture is presented in Figure 3 [6]. The allowable fluctuation degree in asphalt-aggregate ratio is the design value $\pm 0.3 \%$ [6]. In this study, the molding (or rolling) temperature was determined by the range of design value $\pm 15^{\circ} \mathrm{C}$. The effects of variations of these factors on the low-temperature performance of the asphalt mixture were then estimated.

To study the influence of gradation variation on the lowperformance of asphalt mixtures, there is a need to accurately obtain the set gradation. Therefore, the aggregates in different sizes of $13.2-16 \mathrm{~mm}, 9.5-13.2 \mathrm{~mm}, 4.75-9.5 \mathrm{~mm}$, $2.36-4.75 \mathrm{~mm}, 1.18-2.36 \mathrm{~mm}, 0.6-1.18 \mathrm{~mm}, 0.3-0.6 \mathrm{~mm}$, $0.15-0.3 \mathrm{~mm}, 0.075-0.15 \mathrm{~mm}$, and $0-0.075 \mathrm{~mm}$ were sieved and stored separately. Then, the asphalt mixture was 
TABle 2: Properties of the aggregates.

\begin{tabular}{|c|c|c|c|c|c|}
\hline \multicolumn{3}{|c|}{ Item } & Test result & Requirement & Test method \\
\hline \multirow{4}{*}{ Coarse aggregate } & & Crushing value $(\%)$ & 16.9 & $\leq 26$ & T0316 \\
\hline & Loss by & asion and impact of the sample (\%) & 17.5 & $\leq 28$ & T0317 \\
\hline & $9.5-13.2 \mathrm{~mm}$ & Percentage of flat-elongated particles (\%) & 6.9 & $\leq 12$ & T0312 \\
\hline & $4.75-9.5 \mathrm{~mm}$ & Polished stone value & $\begin{array}{l}6.3 \\
46\end{array}$ & $\begin{array}{l}\leq 18 \\
\geq 42\end{array}$ & T0321 \\
\hline \multirow{2}{*}{ Fine aggregate } & & Sand equivalent (\%) & 68 & $\geq 60$ & T 0334 \\
\hline & & Solidness (\%) & 16 & $>12$ & Т 0340 \\
\hline
\end{tabular}

Table 3: Properties of the limestone filler.

\begin{tabular}{lcccc}
\hline \multicolumn{1}{c}{ Item } & & Test result & Requirement & Test method \\
\hline Specific density & & 2.655 & - & T0352 \\
Water content (\%) & $0.6 \mathrm{~mm}$ & 0.4 & 100 & T0332 \\
& $0.15 \mathrm{~mm}$ & 100 & $90-100$ & T0351 \\
Passing (\%) & $0.075 \mathrm{~mm}$ & 91.6 & $75-100$ & T0353 \\
& & 0.3 & $<1$ & T0354 \\
Hydrophilic coefficient & & 3 & $<4$ & \\
Plasticity index (\%) & & & \\
\hline
\end{tabular}

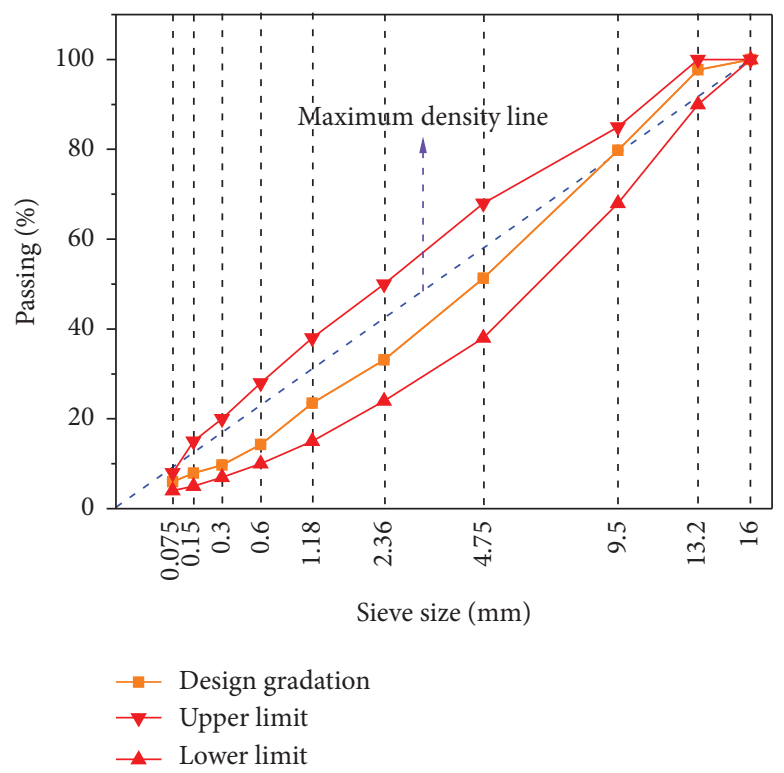

FIGURE 2: Design gradation of the asphalt mixture.

TABLE 4: Test results of asphalt mixture based on the OAR.

\begin{tabular}{lccccc}
\hline OAR (\%) & Air voids (\%) & Voids filled with asphalt (\%) & Voids in mineral aggregate (\%) & Marshall stability (kN) & Marshall flow (0.1 mm) \\
\hline 5.0 & 3.8 & 72.8 & 14.0 & 11.17 & 26.9 \\
- & $3-5$ & $65-75$ & $\geq 13.8$ & $\geq 8.0$ & $20-40$ \\
\hline
\end{tabular}

produced by using these sieved aggregates. The air void of asphalt mixture for each group was determined by Marshall Compaction method, as shown in Table 5.
2.3.2. Gradation Segregation and Temperature Segregation. The gradation segregation and temperature segregation easily occurs during the processes of production, 


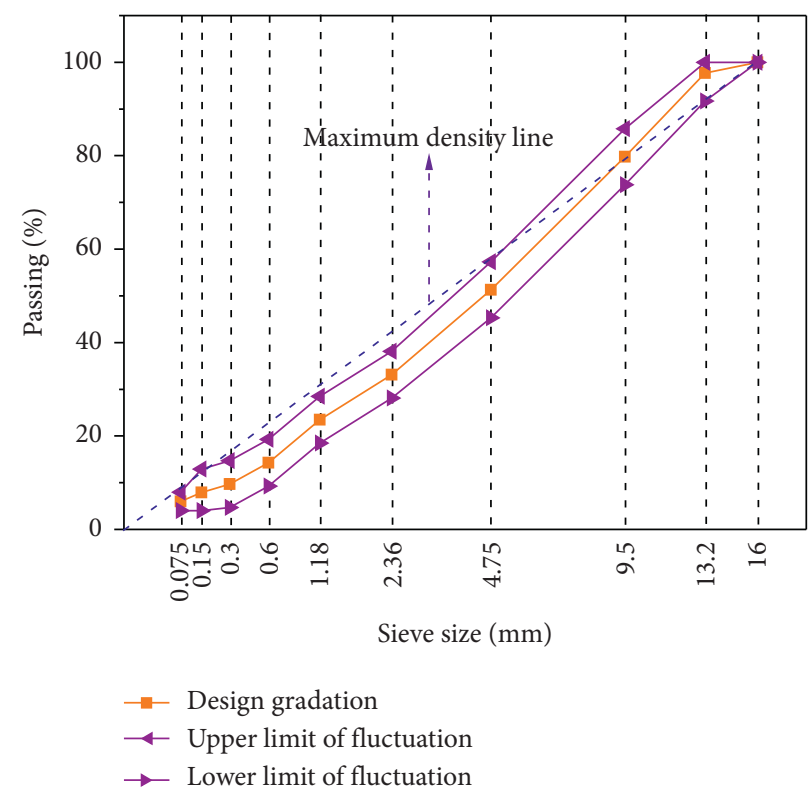

FIGURE 3: Allowable range of fluctuation in the gradation of the asphalt mixture.

TABLE 5: Test results of Marshall compaction.

\begin{tabular}{|c|c|c|c|c|c|}
\hline \multicolumn{2}{|c|}{ Test number } & $\begin{array}{c}\text { Gradation } \\
\text { A }\end{array}$ & \multirow{2}{*}{$\begin{array}{c}\text { Asphalt-aggregate ratio } \\
(\%) \\
\text { B } \\
4.7\end{array}$} & \multirow{2}{*}{$\begin{array}{c}\begin{array}{c}\text { Molding temperature } \\
\left({ }^{\circ} \mathrm{C}\right) \\
\mathrm{C}\end{array} \\
145\end{array}$} & \multirow{2}{*}{$\begin{array}{c}\text { Air voids (\%) } \\
5.0\end{array}$} \\
\hline \multirow{9}{*}{ Orthogonal test (OT) } & 1 & $\begin{array}{l}\text { Upper limit of } \\
\text { fluctuation }\end{array}$ & & & \\
\hline & 2 & $\begin{array}{l}\text { Upper limit of } \\
\text { fluctuation }\end{array}$ & 5.0 & 160 & 3.8 \\
\hline & 3 & $\begin{array}{l}\text { Upper limit of } \\
\text { fluctuation }\end{array}$ & 5.3 & 175 & 2.9 \\
\hline & 4 & Design gradation & 4.7 & 160 & 4.4 \\
\hline & 5 & Design gradation & 5.0 & 175 & 3.5 \\
\hline & 6 & Design gradation & 5.3 & 145 & 3.0 \\
\hline & 7 & Lower limit of fluctuation & 4.7 & 175 & 6.0 \\
\hline & 8 & Lower limit of fluctuation & 5.0 & 145 & 5.8 \\
\hline & 9 & Lower limit of fluctuation & 5.3 & 160 & 4.4 \\
\hline Control group & $\begin{array}{l}\text { Design } \\
\text { gradation }\end{array}$ & 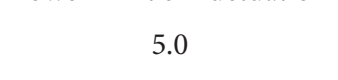 & 160 & 3.7 & \\
\hline
\end{tabular}

transportation, and paving for asphalt mixtures. Existing studies prove that the gradation segregation and temperature segregation have adverse influence on the performance of asphalt mixture [30-34]. But, most of the studies only involve the simulation of large-area segregation, namely, the width of segregation area is near or larger than the rolling width of the roller, as shown in Figure 4(a). However, the large-area segregation rarely occurs during normal construction process of asphalt layers. Furthermore, when the width of segregation area is smaller than the rolling width, the performance of asphalt mixture in the segregation area is not clear, as shown in Figure 4(b). Therefore, this paper mainly focuses on investigating the performance of the asphalt mixture in small-area segregation.

In this study, four levels of gradation segregation were designed, which are shown in Figure 5. The asphalt-aggregate ratio of the control group is obviously inappropriate for the asphalt mixtures with gradation segregation. The most practical method to determine the asphalt-aggregate ratio is by taking the cores from the segregation area of the asphalt pavement. However, this method will destroy the structure of the asphalt pavement. Moreover, there is another method: loose asphalt mixture is separated by passing through different sizes of sieves, such as the $9.5 \mathrm{~mm}$ and the $4.75 \mathrm{~mm}$ sieves [35]. The asphalt mixtures with different gradation segregation and asphalt-aggregate ratio can be obtained by proportioning these parts. But, the loose modified asphalt mixture agglomerates seriously, which is difficult to adjust the proportion of coarse and fine particles. So, the method to obtain the segregated asphalt mixture by sieves has blindness in adjusting the degree of gradation segregation.

The effective thickness of the asphalt film for control group can be calculated according to the information in Tables 6 and 7, and Equation (1). The calculated result is 


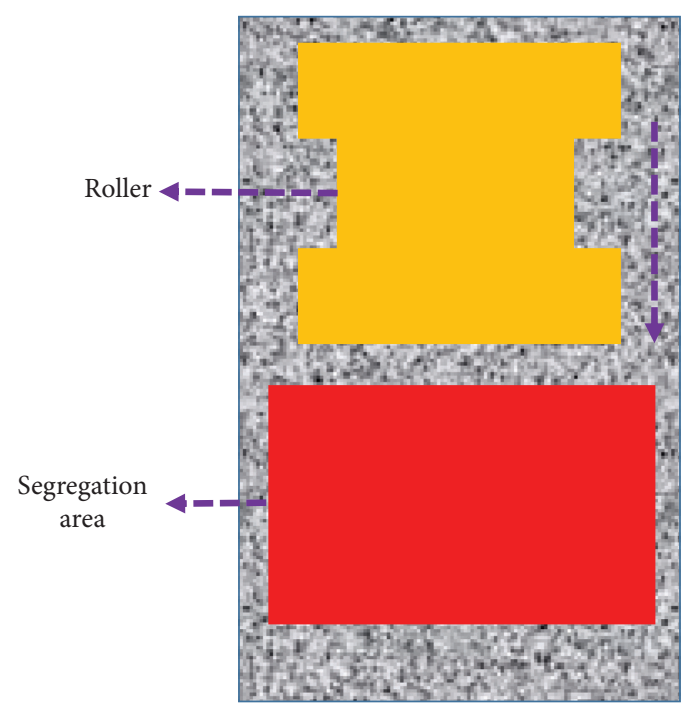

(a)

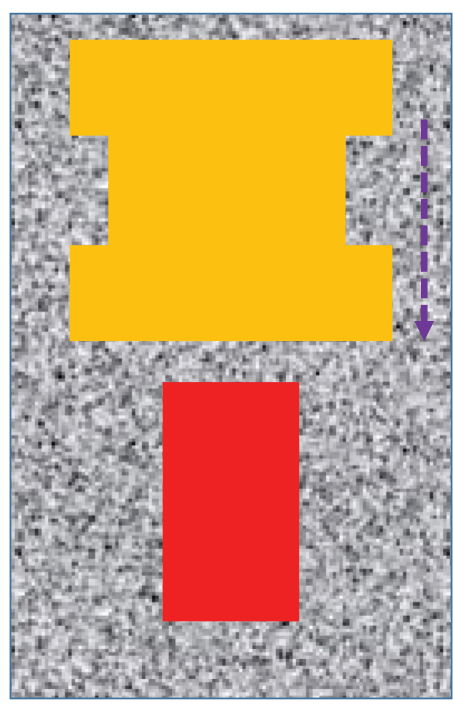

(b)

Figure 4: Schematic diagram of the segregation area: (a) large-area segregation; (b) small-area segregation.

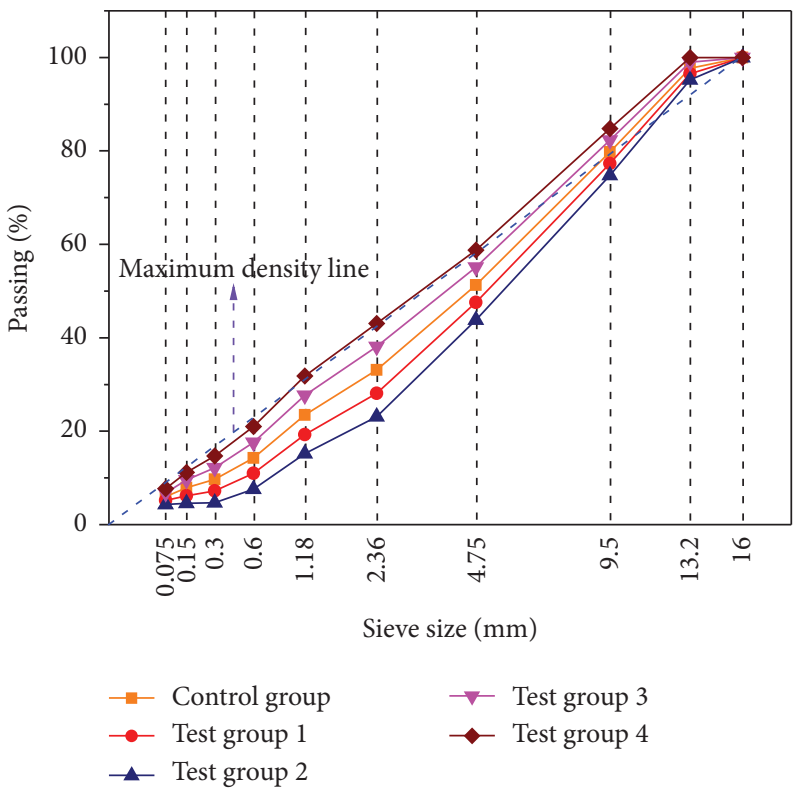

FIGURE 5: Four levels of gradation segregation designed in this study.

TABLE 6: Density test results for the different sizes of aggregates.

\begin{tabular}{|c|c|c|c|c|c|}
\hline Item & $0-2.36 \mathrm{~mm}$ & $2.36-4.75 \mathrm{~mm}$ & $4.75-9.5 \mathrm{~mm}$ & $9.5-13.2 \mathrm{~mm}$ & $13.2-16 \mathrm{~mm}$ \\
\hline Bulk specific gravity & 2.782 & 2.819 & 2.758 & 2.797 & 2.763 \\
\hline Apparent specific gravity & 2.816 & 2.915 & 2.835 & 2.909 & 2.881 \\
\hline Proportion (\%) & 33.1 & 18.2 & 28.5 & 17.9 & 2.3 \\
\hline
\end{tabular}

$7.59 \mu \mathrm{m}$. Since the gradation-segregated asphalt mixture was derived from the controlled asphalt mixture, the effective thickness of asphalt film for gradation-segregated asphalt mixture was considered to be approximately equal to that of the control group for the test groups (TGs) 1-4. If the effective thickness of the asphalt film is known, the effective asphalt content can be determined by back calculation. Then, the asphalt content can be calculated by using Equations (2) 
TABLE 7: Information for the calculation of the effective film thickness of the control group.

Bulk specific gravity of the Apparent specific gravity of Effective specific gravity of Effective asphalt Specific surface area of the combined aggregate the combined aggregate the combined aggregate content $(\%)$ combined aggregate $\left(\mathrm{m}^{2} / \mathrm{kg}\right)$

$\begin{array}{lllll}2.784 & 2.857 & 2.834 & 4.1 & 5.21\end{array}$

and (3) [6]., where DA is the effective thickness of the asphalt film $(\mu \mathrm{m}) ; P_{b e}$ is the effective asphalt content $(\%) ; \gamma_{b}$ is the specific gravity of asphalt $\left(25^{\circ} \mathrm{C} / 25^{\circ} \mathrm{C}\right)$; $\mathrm{SA}$ is the specific surface area of the combined aggregate $\left(\mathrm{m}^{2} / \mathrm{kg}\right) ; P_{b a}$ is the proportion of asphalt absorbed into the aggregate (asphaltaggregate ratio) (\%); $\gamma_{s e}$ is the effective specific gravity of the combined aggregate; $\gamma_{s b}$ is the bulk specific gravity of the combined aggregate; $P_{b}$ is the asphalt content (\%); $P_{s}$ is the ratio of the mass of the aggregates to the mass of the asphalt mixture (\%).

$$
\begin{aligned}
\mathrm{DA} & =\frac{P_{b e}}{\gamma_{b} \times \mathrm{SA}} \times 10, \\
P_{b a} & =\frac{\gamma_{s e}-\gamma_{b}}{\gamma_{s e} \times \gamma_{s b}} \times \gamma_{b} \times 100, \\
P_{b} & =P_{b e}+\frac{P_{b a}}{100} \times P_{s},
\end{aligned}
$$

The calculated asphalt-aggregate ratio can be corrected by [36].

$$
y=1.0475 x-0.0737
$$

where $y$ is the corrected asphalt-aggregate ratio (\%) and $x$ is the calculated asphalt-aggregate ratio (\%). The asphaltaggregate ratios of TGs $1-4$ are presented in Table 8 .

Two levels of temperature segregation were considered in this study, the temperatures of which were set to $145^{\circ} \mathrm{C}$ (TG 5) and $130^{\circ} \mathrm{C}$ (TG 6).

The surface texture ratio can be used to assess the degree of gradation segregation according to NCHRP report 441 [32]. TG 1 belonged to the low-level segregation, and the segregation level of TG 2 was high. Correspondingly, TGs 3 and 4 belonged to the low-level and high-level segregation, respectively. According to the range of temperature differences by NCHRP report 441 [32], TGs 5 and 6 belonged to the low-level and high-level segregation, respectively.

\subsubsection{Determination of Air Voids of Segregated Asphalt} Mixture. According to JTG F40-2004 [6], the OAR was determined using the Marshall design method in China. Because the results of this research were applied to the actual construction project in China, the Marshall design method was adopted for the OAR. However, compared with the Marshall compaction test, the compaction effect of the specimen made by the gyratory compaction test is more close to that of the actual core sample [37]. Therefore, the air voids of segregated asphalt mixtures were determined by using the Superpave compaction method. The influence of nonsegregation area on segregation area was considered in this research. The mesh mold is shown in Figure 6. Firstly, the mass of nonsegregated and segregated asphalt mixtures should be determined for molding specimens. The relationship between the height of the specimen (or air voids) and the gyration number was obtained from the records of Superpave Gyratory Compactor. For road construction projects, the air void of asphalt mixture after being paved is approximately $10 \%$ [38]. The numbers of gyrations were 11 and 63 , respectively, to achieve the air voids of $10 \%$ and $3.7 \%$ (the designed air voids). Since the segregated and nonsegregated asphalt mixtures have the same thickness after being paved, the height of the specimen for segregated asphalt mixture subjected to 11 gyrations should be same as that of nonsegregated asphalt mixture. The mass of the segregated asphalt mixture is determined based on the height. Next, the nonsegregated and segregated asphalt mixtures with the predetermined mass were placed on two sides of the partition, respectively. The mesh mold was marked according to the position of the partition. When the asphalt mixtures on both sides of the partition reached the predetermined molding temperature, the partition was taken out, and the mesh mold with the asphalt mixtures was put into the Superpave Gyratory Compactor for molding. After 63 gyrations, the mesh mold was removed from the Superpave Gyratory Compactor. The specimen was cut into two pieces according to the mark. The air voids of the cut specimens were measured in accordance with T 0705-2011 (JTG E202011) [27], and the results are presented in Table 9. In this study, the ratio of the segregation area to the nonsegregation area was set as 1:1. Different ratios can be obtained by adjusting the width and position of the partition.

2.4. Specimen Preparation and Testing Procedure. The SCB test was selected to evaluate the low-temperature performance of asphalt mixture in accordance with ASTM D804416 [39]. The test temperature used here was $-10^{\circ} \mathrm{C}$. The index of SCB test was $J_{c}$ value, the calculation method of which is shown in Equations (5) and (6) [39].

$$
\begin{aligned}
& J_{c}=\frac{-1}{b}\left(\frac{d U}{d a}\right), \\
& U=\sum_{i=1}^{n}\left[\left(u_{i+1}-u_{i}\right) P_{i}+\frac{1}{2} \times\left(u_{i+1}-u_{i}\right) \times\left(P_{i+1}-P_{i}\right)\right],
\end{aligned}
$$

where $J_{c}$ is the critical strain energy release rate $\left(\mathrm{kJ} / \mathrm{m}^{2}\right) ; b$ is the thickness of specimen (m); $a$ is the incision depth (m); $U$ is the failure strain energy $(\mathrm{kJ}) ; d U / d a$ is the change rate of strain energy with an incision depth $(\mathrm{kJ} / \mathrm{m}) ; P_{i}$ is the force applied by the $i$ loading step $(\mathrm{kN}) ; P_{i+1}$ is the force applied by the $i+1$ loading step $(\mathrm{kN}) ; u_{i}$ is the displacement of the loading rod detected by the instrument during $i$ loading step (m); $u_{i+1}$ is the displacement of the loading rod detected by the instrument during $i$ loading step $(\mathrm{m})$. 
TABle 8: Determination of asphalt-aggregate ratios of TGs 1-4.

\begin{tabular}{lcccccc}
\hline TG & $\mathrm{SA}\left(\mathrm{m}^{2} / \mathrm{kg}\right)$ & $P_{b e}(\%)$ & $\gamma_{s e}$ & $\gamma_{s b}$ & Calculated asphalt-aggregate ratio (\%) & Corrected asphalt-aggregate ratio (\%) \\
\hline 1 & 4.38 & 3.4 & 2.839 & 2.787 & 4.2 & 4.3 \\
2 & 3.51 & 2.7 & 2.846 & 2.791 & 3.5 & 3.6 \\
3 & 6.07 & 4.7 & 2.825 & 2.774 & 5.6 & 5.8 \\
4 & 6.93 & 5.4 & 2.813 & 2.762 & 6.4 & 6.6 \\
\hline
\end{tabular}

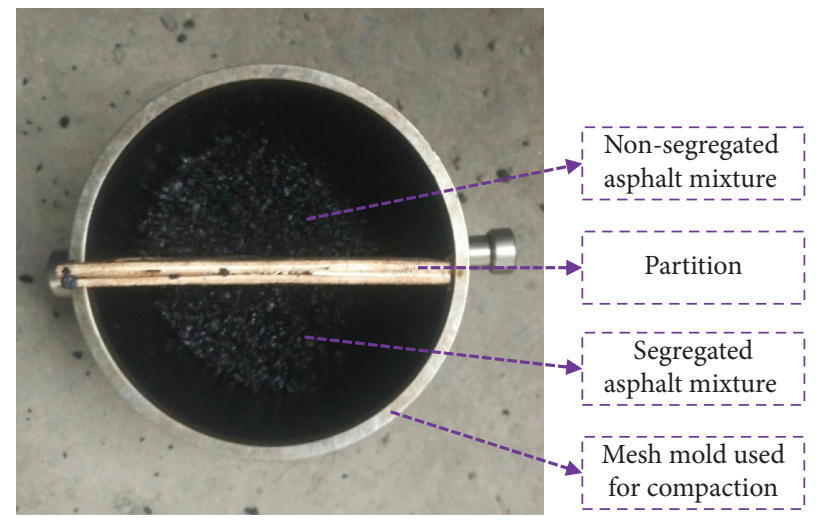

Figure 6: Mesh mold used for compaction.

TABLe 9: Measured air voids of TGs 1-6.

\begin{tabular}{|c|c|c|c|c|c|}
\hline \multicolumn{4}{|c|}{ Gradation segregation } & \multicolumn{2}{|c|}{ Temperature segregation } \\
\hline TG 1 & TG 2 & TG 3 & TG 4 & TG 5 & TG 6 \\
\hline $8.7 \%$ & $10.6 \%$ & $3.1 \%$ & $2.5 \%$ & $4.0 \%$ & $5.3 \%$ \\
\hline
\end{tabular}

In this paper, the OT method was used to evaluate the influences of the variations of aggregate gradation, asphaltaggregate ratio, and initial rolling temperature on lowtemperature performance of the asphalt mixture. The effects of gradation segregation and rolling times on low-temperature performance were considered separately.

2.5. BIM Platform. In this study, a BIM platform was developed to monitor the construction quality of the asphalt pavement intuitively and in real time. There are 4 parts to build a BIM platform: three-dimensional (3D) model of roads and bridges, terrain data, monitoring information, and platform functions. Three-dimensional models can directly show the shape of roads and bridges, and is the carrier of construction information. Terrain data were obtained by oblique photography [40]. The key construction monitoring indices were determined according to the results of the laboratory tests. Construction control information was obtained through different sensors. The functions of the BIM platform were mainly related to the analysis and display of detected data. The building process of the BIM platform is presented in Figure 7.

2.5.1. Three-dimensional Structure of the Asphalt Pavement. Three-dimensional structure of the asphalt pavement was drawn by the software of Autodesk Revit, which can be imported into this BIM platform. The asphalt pavement includes surface course and base course. Based on the location of the start and end of the paving for a truck of asphalt mixture, the 3D structure of the asphalt pavement was divided into many components. The starting point of the component was the starting paving position of the asphalt mixture of a truck. The BIM model of the asphalt pavement is shown in Figure 8.

2.5.2. Building BIM Platform. The monitoring of construction information was based on the BIM platform developed by the authors, which is presented in Figure 9. The terrain data were obtained using the oblique photography, as shown in Figure 9. The construction control indices were measured by different types of sensors in the process of asphalt pavement construction. The detected data were uploaded to the background data processing center through the $4 \mathrm{G}$ network. The detected data are shown on the components of road and bridge in the BIM platform [41]. When you click the component, the test data are displayed. Moreover, the detected data can be analyzed and displayed by the background data processing center. For example, the BIM platform can show the trend of the asphalt-aggregate ratio with time. Software users can log in to the system from anywhere. They can also view and modify the information and models according to their permissions. 


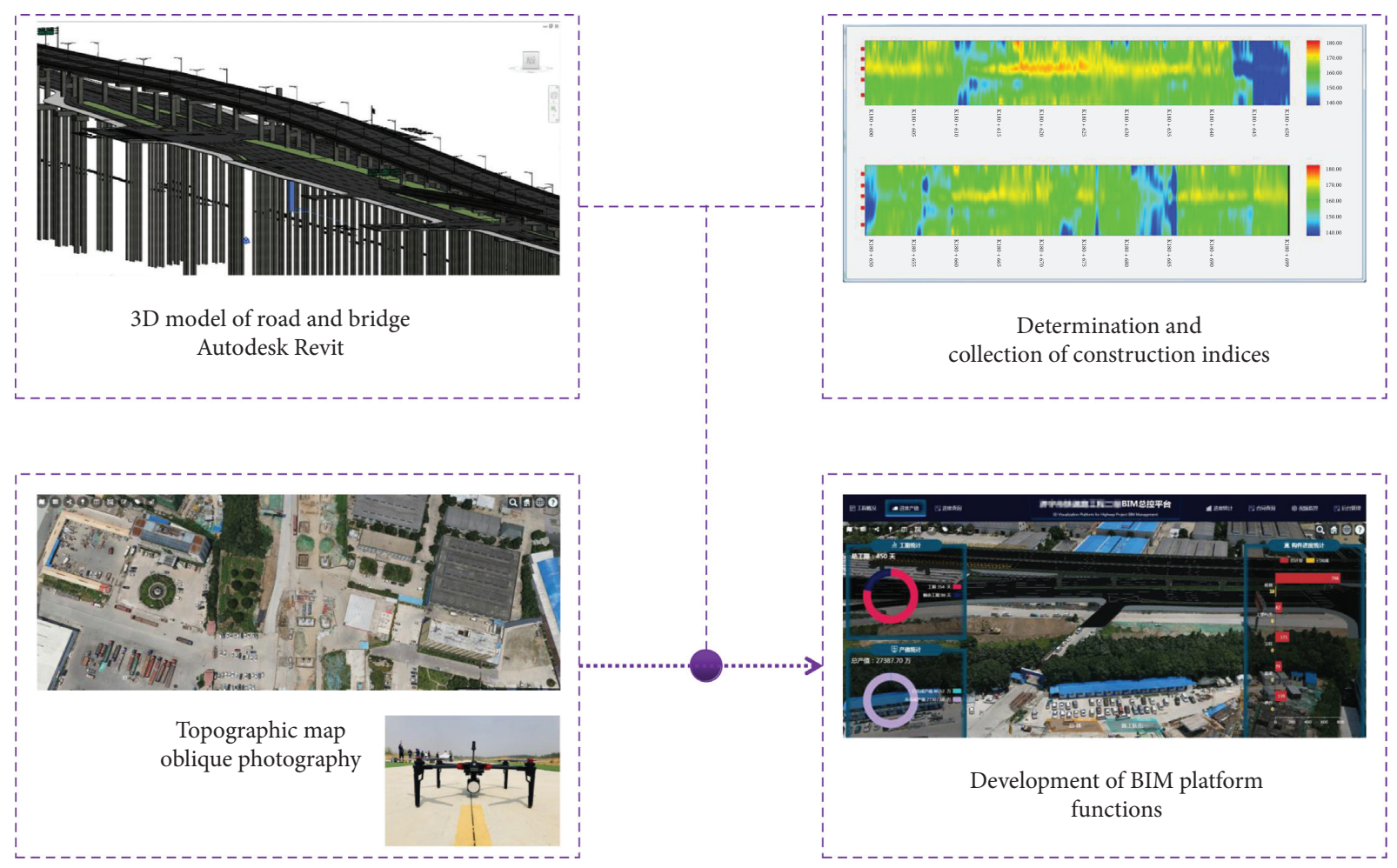

FIgure 7: Process of building the BIM platform.

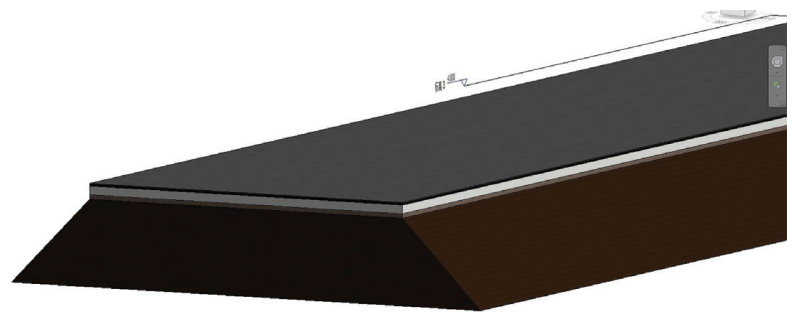

FIgURE 8: Three-dimensional structure of asphalt pavement.

\section{Results and Discussion}

\subsection{Influence of Gradation, Asphalt-Aggregate Ratio, and} Rolling Temperature on Low-Temperature Performance

3.1.1. Range Analysis. The OT results and range analysis of low-temperature performance of the asphalt mixture are shown in Table 10.

In Table $10, I_{j}$ is the sum of $J_{c}$ of level 1 for column $j(j=1$, 2 , and 3$) ; I I_{j}$, is the sum of $J_{c}$ of level 2 for column $j(j=1,2$, and 3); $I I I_{j}$ is the sum of $J_{c}$ of level 3 for column $j(j=1,2$, and 3). $R_{j}$ is the difference between the maximum and minimum values among $I_{j} / 3, I I_{j} / 3$, and $I I I_{j} / 3$.

According to the results of Table 10, the order of influence of various factors on the low-temperature performance of the asphalt mixture from strong to weak is asphaltaggregate ratio, gradation, and rolling temperature. Therefore, in the mixing process of the asphalt mixture, special attention should be paid to the fluctuation of asphaltaggregate ratio to ensure the low-temperature performance of the asphalt mixture.

The effect of each factor level on $J_{c}$ value is shown in Figure 10. It can be seen from the figure that for a given level of influencing factors, the $J_{c}$ value increases first and then decreases as the gradation becomes coarser. This is because when compared with the upper limit and lower limit of fluctuation, the asphalt mixture with design gradation has a higher degree of compactness, smaller air voids, and less internal defects, so that the low-temperature performance is better while the other conditions are the same. The $J_{c}$ value increases as the asphalt-aggregate ratio increases. The reason is that as the asphalt-aggregate ratio increases, the stiffness modulus of the asphalt mixture decreases and the stress relaxation performance increases. Under low-temperature conditions, the failure of the asphalt mixture requires more energy. The $J_{c}$ value increases weakly with the increase of the 


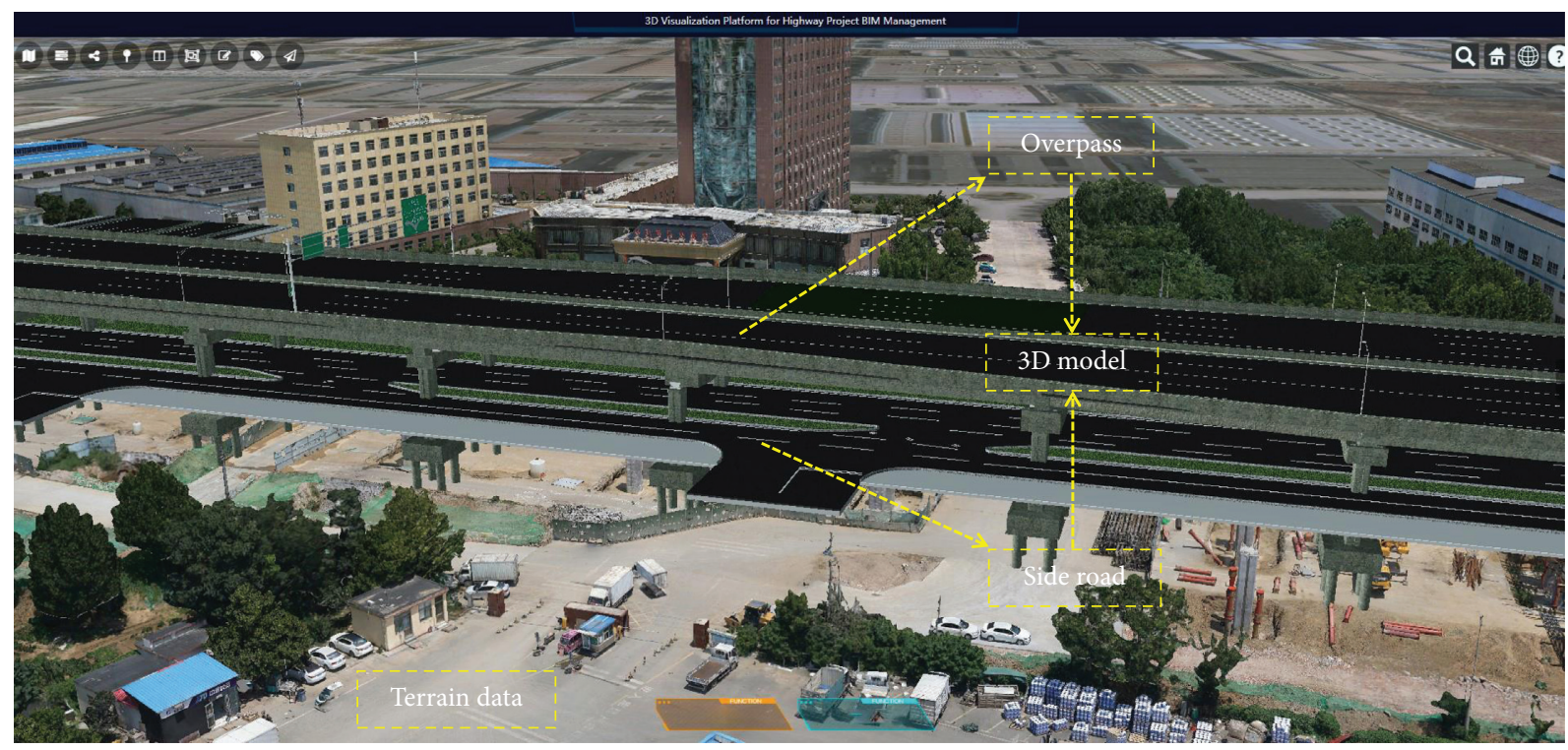

FiguRe 9: Interface of the BIM platform.

rolling temperature when the other conditions are the same. Increasing the rolling temperature will improve the viscosity of asphalt and promote the compaction. On the other hand, the increase effect is not obvious because the three rolling temperatures are at a higher level.

3.1.2. Variance Analysis. The variance analysis results are presented in Tables 11 and 12., where $Y_{i}$ is the average value of $J_{c}$ for each group; $Q_{T}$ is the total sum of squares of deviations.

$$
\begin{aligned}
K & =\sum_{i=1}^{9} Y_{i}, \\
P & =\frac{1}{9} K^{2}, \\
W & =\sum_{i=1}^{9} Y_{i}^{2}, \\
U_{A} & =\frac{1}{3}\left[\left(I_{1}\right)^{2}+\left(I I_{1}\right)^{2}+\left(I I I_{1}\right)^{2}\right], \\
U_{B} & =\frac{1}{3}\left[\left(I_{2}\right)^{2}+\left(I I_{21}\right)^{2}+\left(I I_{2}\right)^{2}\right], \\
U_{C} & =\frac{1}{3}\left[\left(I_{3}\right)^{2}+\left(I I_{3}\right)^{2}+\left(I I I_{3}\right)^{2}\right], \\
U_{D} & =\frac{1}{3}\left[\left(I_{4}\right)^{2}+\left(I I_{4}\right)^{2}+\left(I I I_{4}\right)^{2}\right], \\
Q_{A} & =U_{A}-P, \\
Q_{B} & =U_{B}-P, \\
Q_{C} & =U_{C}-P, \\
Q_{D} & =U_{D}-P, \\
Q_{T} & =W-P,
\end{aligned}
$$

For $\alpha=5 \%, F_{\alpha}(2,2)$ is 19 . So $F$-value of factor $B$ is higher than $F_{\alpha}(2,2)$, while $F$-values of factors $A$ and $C$ are less than $F_{\alpha}(2,2)$, which indicates that the factor $B$ significantly affects the low-temperature of the asphalt mixture, and the influence of factors $A$ and $C$ on evaluation index is not obvious. Therefore, to ensure the low-temperature performance of the asphalt mixture, the asphalt mixture plant should focus on monitoring the fluctuation of asphalt-aggregate ratio, especially when the asphalt-aggregate ratio is lower than the set value.

\subsection{Influence of Segregation on Low Temperature} Performance. The SCB test results of segregated asphalt mixture are shown in Figure 11.

As shown in Figure 11, for the segregated asphalt mixture, the low-temperature performance decreases as the gradation becomes coarse. This is because the internal defects increases, the asphalt content decreases, and the stiffness modulus increases when the gradation of asphalt mixture becomes coarse. As the gradation becomes fine, the low-temperature performance of asphalt mixture increases. The reason is that the increase of the asphalt content is advantageous for improving the low-temperature performance, and the lower void ratio reduces the internal defects in the mixture. It should be pointed out that the gradation becoming fine and the increase of asphalt content can increase the risk of rutting during hot summers. The selection of types of the asphalt binder can be considered to balance the low-temperature and high-temperature performances of the asphalt mixture. As the degree of temperature segregation increases, the low-temperature performance of the asphalt mixture declines. This is because the asphalt mixture has low degree of compaction and more internal defects, and the asphalt content is relatively reduced, so the adhesion of the asphalt mixture is poor, resulting in a decrease in lowtemperature performance. 
TABLE 10: OT results and range analysis.

\begin{tabular}{lcccc}
\hline & Gradation & Asphalt-aggregate ratio $(\%)$ & Molding temperature $\left({ }^{\circ} \mathrm{C}\right)$ \\
Test number & $\mathrm{A}$ & $\mathrm{B}$ & $\mathrm{C}$ & 3 \\
& 1 & 2 & 145 & $J_{c}\left(\mathrm{~kJ} / \mathrm{m}^{2}\right)$ \\
\hline 1 & Upper limit of fluctuation & 4.7 & 160 & 175 \\
2 & Upper limit of fluctuation & 5.0 & 160 & 1.689 \\
3 & Upper limit of fluctuation & 5.3 & 175 & 1.858 \\
4 & Design gradation & 4.7 & 175 & 1.759 \\
5 & Design gradation & 5.0 & 145 & 1.015 \\
6 & Design gradation & 5.3 & 160 & 1.986 \\
7 & Lower limit of fluctuation & 4.7 & 5.440 & 1.553 \\
8 & Lower limit of fluctuation & 5.0 & 5.453 \\
9 & Lower limit of fluctuation & 5.3 & 5.639 \\
$I_{j}$ & 5.618 & 5.001 & 1.813 \\
$I I_{j}$ & 5.760 & 5.638 & 1.818 \\
$I I I_{j}$ & 5.154 & 5.893 & - \\
$I_{j} / 3$ & 1.873 & 1.667 & 1.880 \\
$I I_{j} / 3$ & 1.920 & 1.879 & - \\
$I I I_{j} / 3$ & 1.718 & 1.964 & - \\
$R_{j}$ & 0.202 & 0.297 & - \\
\hline
\end{tabular}

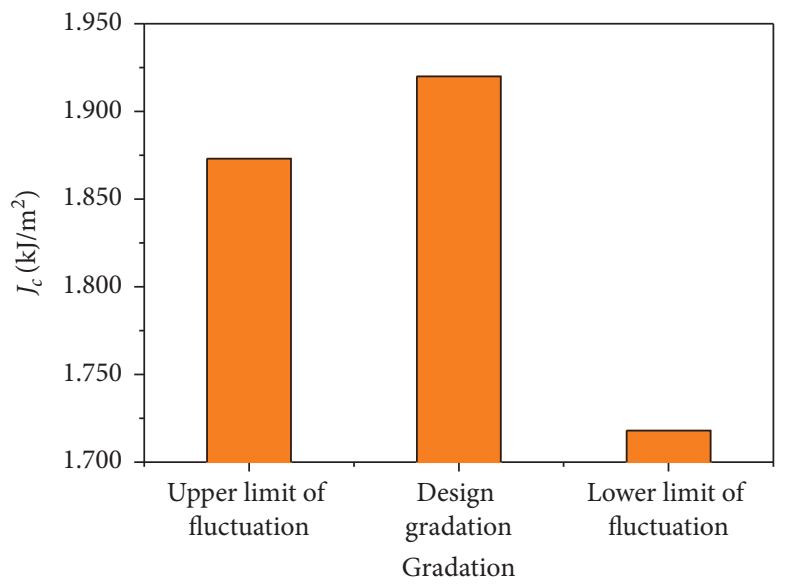

(a)

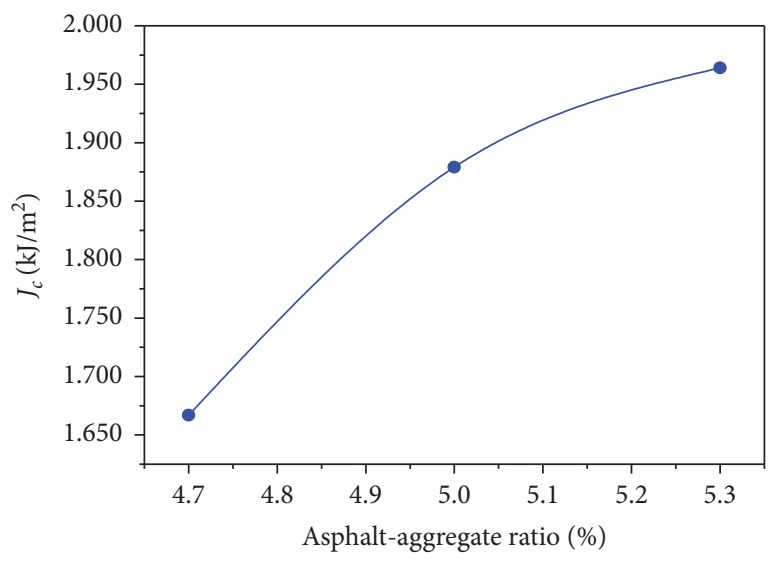

(b)

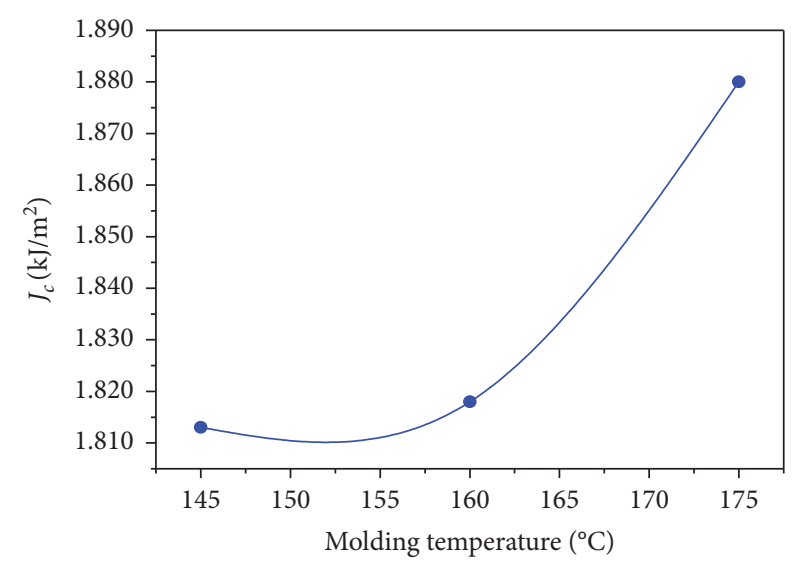

(c)

FigURE 10: Influence of factor levels on low-temperature performance. 
TABLE 11: Calculation process of variance analysis.

\begin{tabular}{|c|c|c|c|c|c|}
\hline Test number & $\begin{array}{c}\text { Gradation } \\
\text { A } \\
1 \\
\end{array}$ & $\begin{array}{c}\text { Asphalt-stone ratio (\%) } \\
\text { B } \\
2 \\
\end{array}$ & $\begin{array}{c}\text { Molding temperature }\left({ }^{\circ} \mathrm{C}\right) \\
\mathrm{C} \\
3 \\
\end{array}$ & $J_{c}\left(\mathrm{~kJ} / \mathrm{m}^{2}\right)$ & Square \\
\hline 1 & Upper limit of fluctuation & 4.7 & 145 & $1.689\left(Y_{1}\right)$ & 2.853 \\
\hline 2 & Upper limit of fluctuation & 5.0 & 160 & $1.858\left(Y_{2}\right)$ & 3.452 \\
\hline 3 & Upper limit of fluctuation & 5.3 & 175 & $2.071\left(Y_{3}\right)$ & 4.289 \\
\hline 4 & Design gradation & 4.7 & 160 & $1.759\left(Y_{4}\right)$ & 3.094 \\
\hline 5 & Design gradation & 5.0 & 175 & $2.015\left(Y_{5}\right)$ & 4.060 \\
\hline 6 & Design gradation & 5.3 & 145 & $1.986\left(Y_{6}\right)$ & 3.944 \\
\hline 7 & Lower limit of fluctuation & 4.7 & 175 & $1.553\left(Y_{7}\right)$ & 2.412 \\
\hline 8 & Lower limit of fluctuation & 5.0 & 145 & $1.765\left(Y_{8}\right)$ & 3.115 \\
\hline 9 & Lower limit of fluctuation & 5.3 & 160 & $1.836\left(Y_{9}\right)$ & 3.371 \\
\hline$I_{j}$ & 5.618 & 5.001 & 5.440 & $K=16.532$ & $W=30.590$ \\
\hline$I I_{j}$ & 5.760 & 5.638 & 5.453 & - & - \\
\hline$I I I_{j}$ & 5.154 & 5.893 & 5.639 & - & - \\
\hline$U$ & 30.434 & 30.508 & 30.376 & $P=30.367$ & - \\
\hline$Q$ & 0.067 & 0.141 & 0.008 & - & - \\
\hline
\end{tabular}

TABLE 12: Variance analysis results.

\begin{tabular}{lcccc}
\hline- & Dispersion & Degree of freedom & Mean square deviation & $F$-value \\
\hline$A$ & 0.067 & 2 & 0.033 & 9.616 \\
$B$ & 0.141 & 2 & 0.070 & 20.206 \\
$C$ & 0.008 & 2 & 0.004 & 1.186 \\
Error & 0.007 & 2 & 0.003 & - \\
Total & 0.223 & 8 & - & - \\
\hline
\end{tabular}

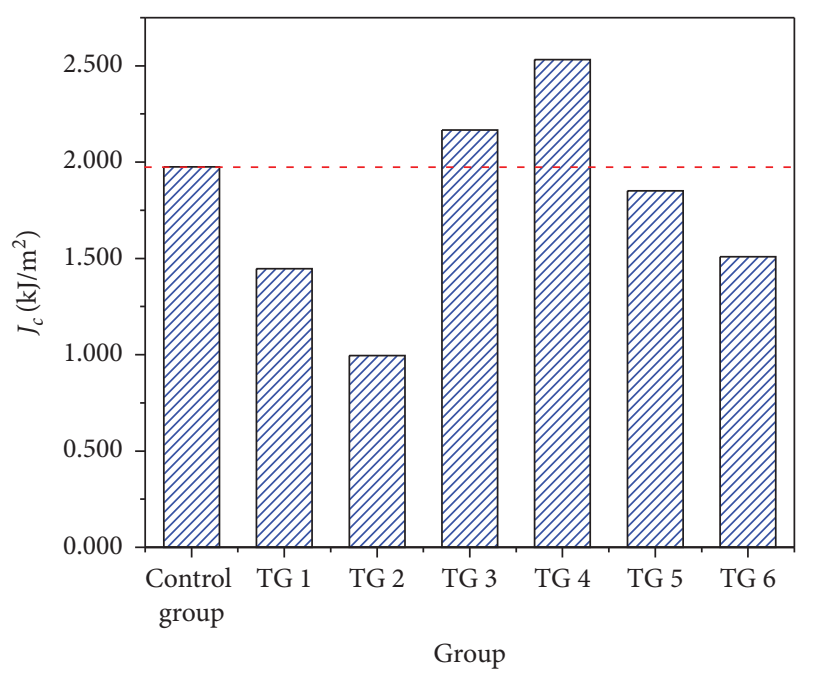

FIgURE 11: SCB test results of the segregated asphalt mixture.

3.3. Comprehensive Analysis of Various Factors on LowTemperature Performance. To compare the influence degree of various factors on the low-temperature performance in the construction process of the asphalt mixture, it is necessary to add a supplementary test group to reflect the difference of low-temperature performance between the asphalt mixture with gradation of lower limit of fluctuation and the control group, as shown in Table 13. The difference of low-temperature performance between asphalt mixture in OT 4, TG 2, TG 4, TG 6, and the control group can, respectively, reflect the influence of the asphalt-aggregate ratio in the mixing process, the coarser and finer gradation due to segregation, and temperature segregation on the lowtemperature performance of the asphalt mixture. For the construction process of the asphalt layer, the effects of various factors on the low-temperature performance of asphalt mixture are shown in Table 14.

According to Table 14, comparing the low-temperature performance of the asphalt mixture of OT 4, supplementary TG 1, TG 2, TG 4, and TG 6, the influence degree order of 
TABLE 13: Low temperature performance of supplementary TGs.

\begin{tabular}{|c|c|c|c|c|c|}
\hline Supplementary TG & Gradation & Asphalt-aggregate ratio (\%) & Molding temperature $\left({ }^{\circ} \mathrm{C}\right)$ & Air voids (\%) & $J_{c}\left(\mathrm{~kJ} / \mathrm{m}^{2}\right)$ \\
\hline 1 & Lower limit of fluctuation & 5.0 & 160 & 5.5 & 1.781 \\
\hline
\end{tabular}

TABLE 14: Influence degree of various factors on low-temperature performance.

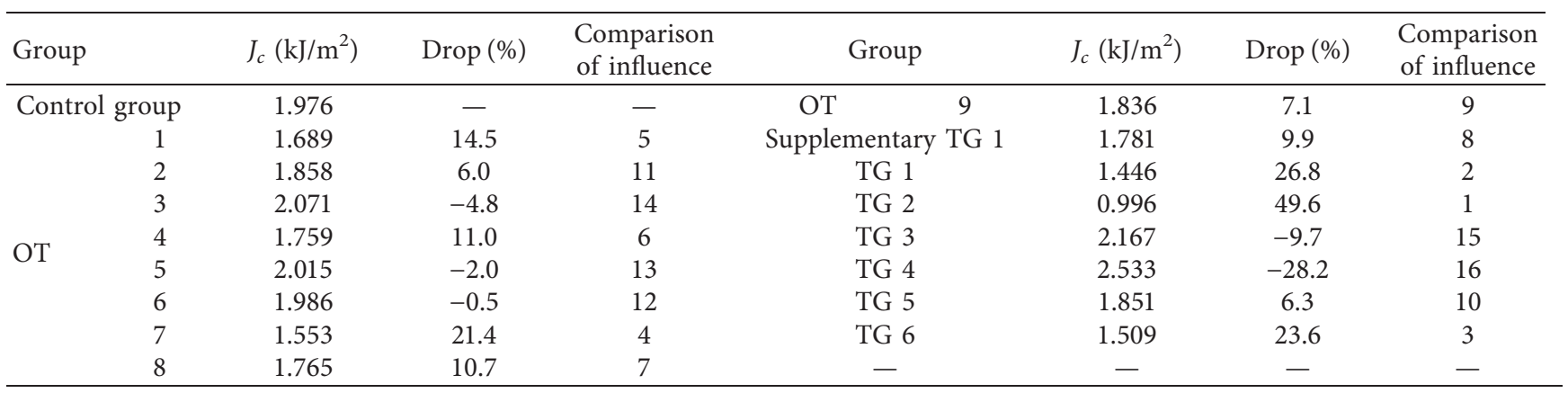

the considered factors for the low-temperature performance from large to small is the gradation coarsening due to segregation, temperature segregation, the reduction of asphalt-aggregate ratio in the mixing process, and the gradation coarsening in the mixing process. The finer gradation due to segregation has a beneficial effect on the lowtemperature performance of the asphalt mixture. Therefore, to ensure the low-temperature performance of the asphalt mixture, it is important to monitor the gradation coarsening and temperature variation caused by the segregation.

3.4. Prediction Model of Critical Strain Energy Release Rate. The critical strain energy release rate is related to the lowtemperature cracking of the asphalt pavement. Therefore, it can be used to characterize the low-temperature performance of asphalt mixtures. The low-temperature performance of asphalt mixtures is related to the properties of raw materials, asphalt-aggregate ratio, and volume parameters [42]. According to the construction process of asphalt layers, the volume parameters also mainly depend on mineral graduation, asphalt-stone ratio, rolling temperature, and so on. These construction indices can be detected in real time by the sensors. Consequently, it is necessary to find out how to use these data to evaluate the low-temperature performance of the asphalt layers during the construction process. In this study, a new prediction model of critical strain energy release rate was established according to Tables 10, 13, and 14, which is shown in Equation (8). Based on these real-time detection data, the construction quality for the lowtemperature performance can be evaluated by this prediction model [43].

$$
\begin{aligned}
\frac{J_{c}}{J_{c d}} & =1.833\left(\frac{P_{a}}{P_{a d}}\right)^{0.852}\left(\frac{T}{T_{d}}\right)^{0.486}(\mathrm{CA})^{-0.737}\left(\mathrm{FA}_{c}\right)^{1.118}\left(\mathrm{FA}_{f}\right)^{-0.157}, \\
R^{2} & =0.929 .
\end{aligned}
$$

, where $J_{c d}$ is the designed critical strain energy release rate, which is a fixed value for a specific project $\left(\mathrm{kJ} / \mathrm{m}^{2}\right) ; P_{a}$ is the detected asphalt-stone ratio; $P_{a d}$ is the designed asphaltstone ratio; $T$ is the rolling temperature $\left({ }^{\circ} \mathrm{C}\right) ; T_{d}$ is the designed rolling temperature $\left({ }^{\circ} \mathrm{C}\right)$; $\mathrm{CA}$ is coarse aggregate ratio; $\mathrm{FA}_{c}$ is fine aggregate coarse fraction ratio; $\mathrm{FA}_{f}$ is fine aggregate fine fraction ratio. With the development of realtime detection technology, the establishment of the model can consider more factors to improve the accuracy and applicability of prediction. Figure 12 presents the estimated $J_{c}$ based on Tables 10, 13, and 14, and Equation (8), compared with the measured $J_{c}$ shown in Table 14. As presented in Figure 12, Equation (8) has high $R$-square values, which indicate how well the measured and estimated values of $J_{c}$ correlate linearly.

After the prediction model of critical strain energy release rate is established, it needs to be verified based on road construction projects. Figure 13 and Table 15 present the gradations and asphalt-stone ratios of the asphalt mixture sampled from the highway construction project in China by the extraction tests (ETs), respectively. The asphalt mixture was prepared according to the results of the ETs. The molding temperature is shown in Table 16, which is measured by the infrared temperature sensors.

The applicability of the prediction model of critical strain energy release rate was evaluated by using the deviation between the estimated and the measured values of each extraction test group. According to Figure 14, the average deviation between the predicted and the measured values of critical strain energy release rate of the extraction groups is $-1.46 \%$. The maximum deviation of these extraction test groups is $12.25 \%$. Overall, the deviation between the predicted and measured values of the critical strain energy release rate of these extraction test groups is relatively small, indicating that the prediction model of the critical strain energy release rate established in this study has good applicability for AC-13. According to Report FHWA/LA.14/ 558 [44], the minimum $J_{c}$ values of 0.6 and $0.5 \mathrm{~kJ} / \mathrm{m}^{2}$ are 


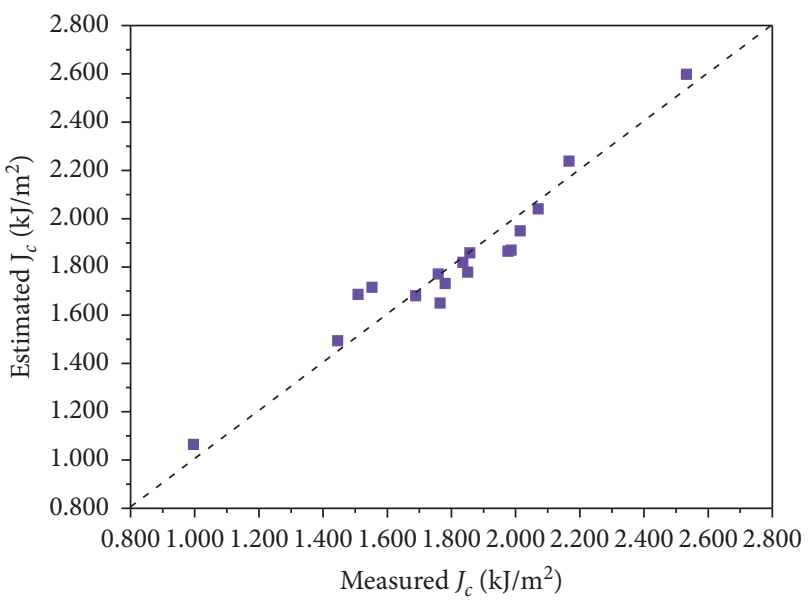

FIgURE 12: Comparisons of measured and estimated $J_{c}$.

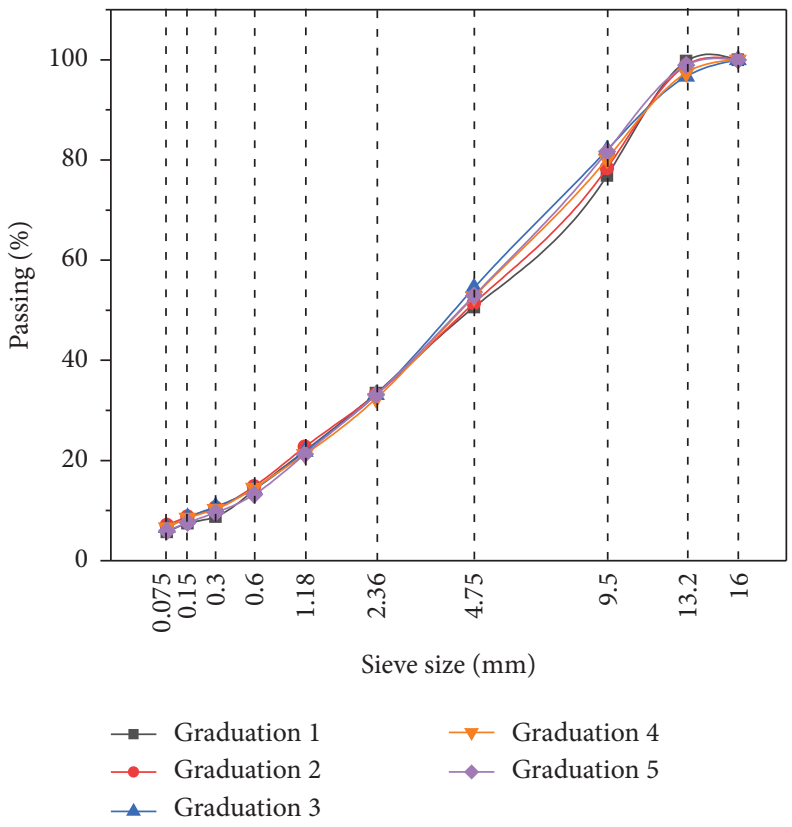

FIgURE 13: Gradations of the asphalt mixture by the ETs.

TABLE 15: Asphalt-stone ratio of the asphalt mixture by the ETs.

\begin{tabular}{lccccc}
\hline Number of the ET & 1 & 2 & 3 & 4 & 5 \\
\hline Asphalt-stone ratio (\%) & 4.7 & 5.3 & 5.2 & 5.2 & 4.8 \\
\hline
\end{tabular}

TABLE 16: Molding temperatures of the asphalt mixture.

\begin{tabular}{lccccc}
\hline Number of the ET & 1 & 2 & 3 & 4 & 5 \\
\hline Molding temperature $\left({ }^{\circ} \mathrm{C}\right)$ & 151 & 156 & 167 & 160 & 149 \\
\hline
\end{tabular}

proposed as the cracking performance criteria to ensure acceptable cracking performance of Level 2 and Level 1 asphalt mixtures, respectively. In this research, if the estimated $J_{c}$ value exceeds $0.6 \mathrm{~kJ} / \mathrm{m}^{2}$, the low-temperature performance of the asphalt layer is considered as qualified.

\subsection{Monitoring the Construction Indices Based on the BIM Platform}

3.5.1. Gradation and Asphalt-Aggregate Ratio of the Asphalt Mixture. The gradation of the asphalt mixture in the mixing stage can be obtained in real time by digital image processing technology $[11,12,45]$ or online detection of asphalt mixture plant $[6,7]$. The asphalt-aggregate ratio in the mixing stage can also be measured by online detection of the asphalt mixture plant [6]. To date, for a pot of asphalt mixture, the information collection system of the asphalt mixture plant can collect the mass of asphalt and hot aggregates for mixing. Therefore, the asphalt-aggregate ratio for each pot can be accurately determined, as shown in Table 17. Moreover, the gradation of a pot of asphalt mixture can be calculated based on the aggregate gradation of each bin. For the highway 


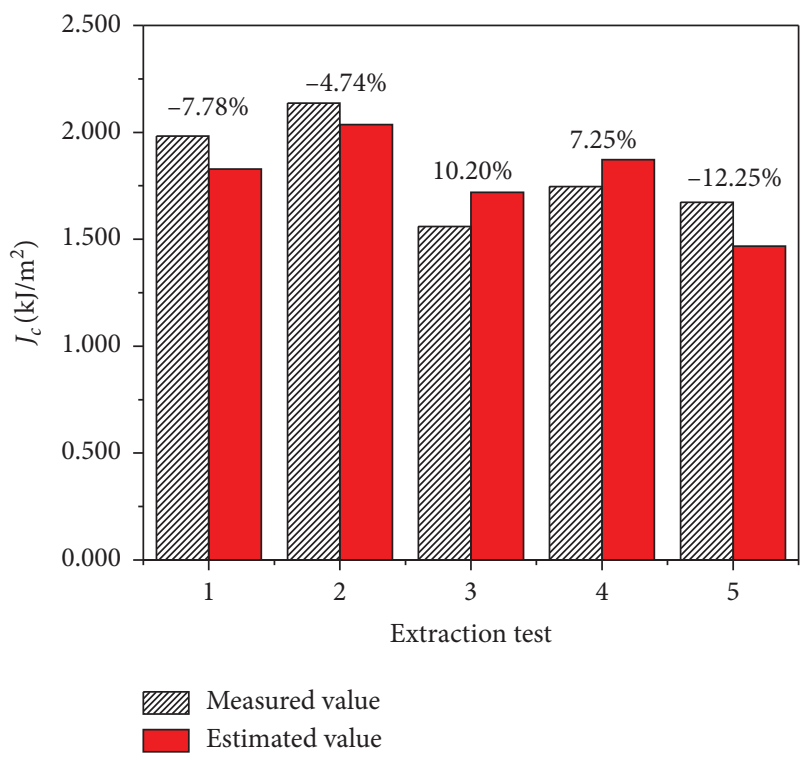

FIGURE 14: Comparison between the predicted and measured values of the SCB test.

TABle 17: Asphalt-stone ratio determined by online detection of asphalt mixture plant.

\begin{tabular}{|c|c|c|c|c|c|c|}
\hline Materials & Bin \#1 $10-15 \mathrm{~mm}$ & Bin \#2 5-10 mm & Bin \#3 $3-5 \mathrm{~mm}$ & Bin $\# 40-3 \mathrm{~mm}$ & Bin \#5 limestone filler & Asphalt \\
\hline Mass (kg) & 480 & 589 & 282 & 567 & 142 & 105 \\
\hline Ratio (\%) & 27.5 & 28.6 & 13.7 & 27.5 & 6.9 & NA \\
\hline Asphalt-stone ratio (\%) & & & 5.1 & & & \\
\hline
\end{tabular}

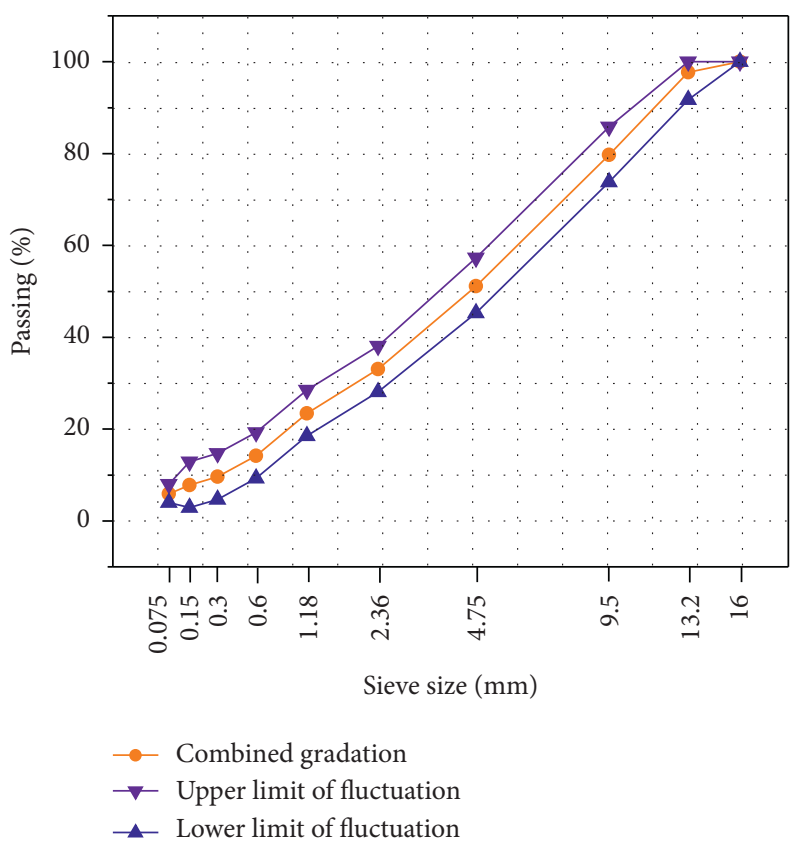

Figure 15: Gradation by online detection of the asphalt mixture plant.

construction project in China, the online test results of the asphalt-stone ratio of every pot of asphalt mixture are shown in Table 17. The online test results show that the fluctuation of asphalt-stone ratio is very small. The real-time gradation of a pot of asphalt mixture is presented in Figure 15.
3.5.2. Initial Rolling Temperature. The infrared temperature sensor can be used to determine the initial rolling temperature. The roller with the infrared temperature sensor is shown in Figure 16. When using the infrared temperature sensor for collecting temperature data, the temperature data and the 


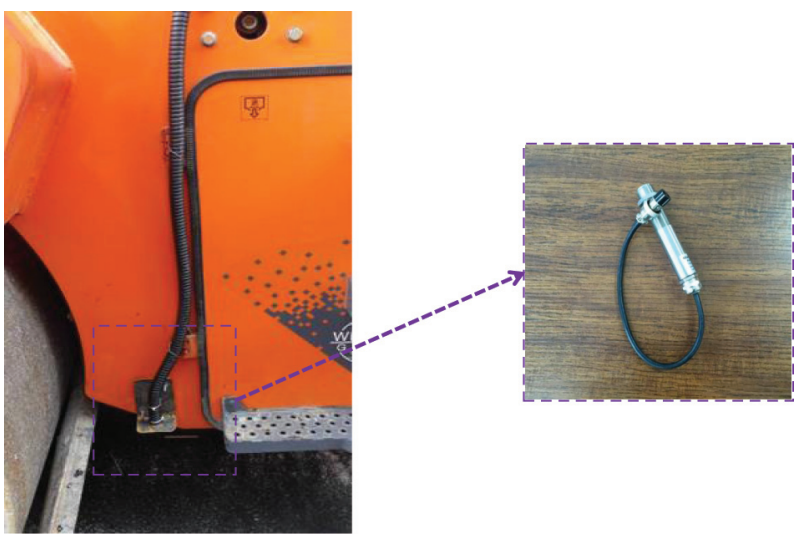

FIgURE 16: Roller with the infrared temperature sensor.

Table 18: Measured initial rolling temperatures of the paving unit of $\mathrm{K} 11+986.2$ to $\mathrm{K} 12+44.1\left({ }^{\circ} \mathrm{C}\right)$.

\begin{tabular}{|c|c|c|c|c|c|c|c|}
\hline Stake mark & Temperature & Stake mark & Temperature & Stake mark & Temperature & Stake mark & Temperature \\
\hline $\mathrm{K} 11+994.29$ & 153.00 & $\mathrm{~K} 12+010.20$ & 179.00 & $\mathrm{~K} 12+023.58$ & 153.00 & $\mathrm{~K} 12+034.75$ & 145.00 \\
\hline $\mathrm{K} 11+994.41$ & 153.00 & $\mathrm{~K} 12+010.22$ & 172.00 & $\mathrm{~K} 12+023.58$ & 153.00 & $\mathrm{~K} 12+035.07$ & 160.00 \\
\hline $\mathrm{K} 11+997.38$ & 161.00 & $\mathrm{~K} 12+011.30$ & 172.00 & $\mathrm{~K} 12+024.11$ & 152.00 & $\mathrm{~K} 12+036.82$ & 148.00 \\
\hline $\mathrm{K} 12+001.01$ & 153.00 & $\mathrm{~K} 12+011.80$ & 175.00 & $\mathrm{~K} 12+024.54$ & 152.00 & $\mathrm{~K} 12+036.99$ & 145.00 \\
\hline $\mathrm{K} 12+001.86$ & 152.00 & $\mathrm{~K} 12+012.60$ & 175.00 & $\mathrm{~K} 12+025.05$ & 157.00 & $\mathrm{~K} 12+037.17$ & 145.00 \\
\hline $\mathrm{K} 12+002.75$ & 167.00 & $\mathrm{~K} 12+013.73$ & 145.00 & $\mathrm{~K} 12+026.25$ & 157.00 & $\mathrm{~K} 12+038.52$ & 142.00 \\
\hline $\mathrm{K} 12+002.82$ & 168.00 & $\mathrm{~K} 12+013.93$ & 145.00 & $\mathrm{~K} 12+026.65$ & 147.00 & $\mathrm{~K} 12+038.90$ & 142.00 \\
\hline $\mathrm{K} 12+003.22$ & 159.00 & $\mathrm{~K} 12+014.07$ & 151.00 & $\mathrm{~K} 12+027.92$ & 147.00 & $\mathrm{~K} 12+039.25$ & 147.00 \\
\hline $\mathrm{K} 12+003.54$ & 158.00 & $\mathrm{~K} 12+015.72$ & 151.00 & $\mathrm{~K} 12+028.39$ & 168.00 & $\mathrm{~K} 12+039.53$ & 147.00 \\
\hline $\mathrm{K} 12+004.15$ & 158.00 & $\mathrm{~K} 12+016.06$ & 159.00 & $\mathrm{~K} 12+028.76$ & 168.00 & $\mathrm{~K} 12+040.88$ & 142.00 \\
\hline $\mathrm{K} 12+004.30$ & 171.00 & $\mathrm{~K} 12+016.17$ & 159.00 & $\mathrm{~K} 12+029.23$ & 155.00 & $\mathrm{~K} 12+040.99$ & 151.00 \\
\hline $\mathrm{K} 12+005.21$ & 155.00 & $\mathrm{~K} 12+017.28$ & 145.00 & $\mathrm{~K} 12+030.53$ & 155.00 & $\mathrm{~K} 12+041.23$ & 152.00 \\
\hline $\mathrm{K} 12+005.38$ & 158.00 & $\mathrm{~K} 12+018.19$ & 145.00 & $\mathrm{~K} 12+030.87$ & 153.00 & $\mathrm{~K} 12+041.33$ & 152.00 \\
\hline $\mathrm{K} 12+006.19$ & 171.00 & $\mathrm{~K} 12+018.61$ & 147.00 & $\mathrm{~K} 12+031.60$ & 153.00 & $\mathrm{~K} 12+042.16$ & 170.00 \\
\hline $\mathrm{K} 12+006.87$ & 158.00 & $\mathrm{~K} 12+019.89$ & 149.00 & $\mathrm{~K} 12+031.82$ & 142.00 & $\mathrm{~K} 12+042.96$ & 170.00 \\
\hline $\mathrm{K} 12+007.52$ & 176.00 & $\mathrm{~K} 12+020.31$ & 152.00 & $\mathrm{~K} 12+032.67$ & 142.00 & $\mathrm{~K} 12+043.41$ & 135.00 \\
\hline $\mathrm{K} 12+008.53$ & 179.00 & $\mathrm{~K} 12+021.03$ & 152.00 & $\mathrm{~K} 12+032.98$ & 144.00 & - & - \\
\hline $\mathrm{K} 12+008.75$ & 160.00 & $\mathrm{~K} 12+021.54$ & 153.00 & $\mathrm{~K} 12+033.82$ & 144.00 & - & - \\
\hline $\mathrm{K} 12+009.66$ & 166.00 & $\mathrm{~K} 12+022.43$ & 153.00 & $\mathrm{~K} 12+034.40$ & 145.00 & - & - \\
\hline
\end{tabular}

asphalt pavement location will be uploaded to the background data processing center. In the background data processing center, the collected temperature values are matched with the asphalt pavement location, as shown in Table 18. The average initial rolling temperature was $155^{\circ} \mathrm{C}$ for the paving unit of $\mathrm{K} 11+986.2$ to $\mathrm{K} 12+44.1$. Then, the temperature data are released to the BIM platform in a timely manner.

3.5.3. Real-Time Monitoring of Construction Indices. The measured or predicted values of key construction control indices were uploaded to the BIM platform in real time, which were associated with the BIM components of road or bridge through the BIM platform. When a BIM component is clicked with the mouse, the construction information will be displayed near the BIM component. Construction workers can log in to the system to view the 3D models and monitor the data of construction quality at any location and time. Figure 17 shows the construction information of a BIM composition. The passing of $2.36 \mathrm{~mm}$ sieve can be used to distinguish between fine- and coarse-graded mixtures for AC-13 (AASHTO M 323-17) [46], which is the primary control sieve. Therefore, the passing of the $2.36 \mathrm{~mm}$ sieve was used to characterize the gradation of the asphalt mixture. The pile numbers of BIM components were determined by GPS-RTK technology [29]. According to Equation (8), the estimated value of $J_{c}$ was $1.870 \mathrm{~kJ} / \mathrm{m}^{2}$ for this BIM component. Table 19 presents the allowable ranges of fluctuation for these construction indices. In addition, the measured values of construction indices can also be analyzed centrally. 


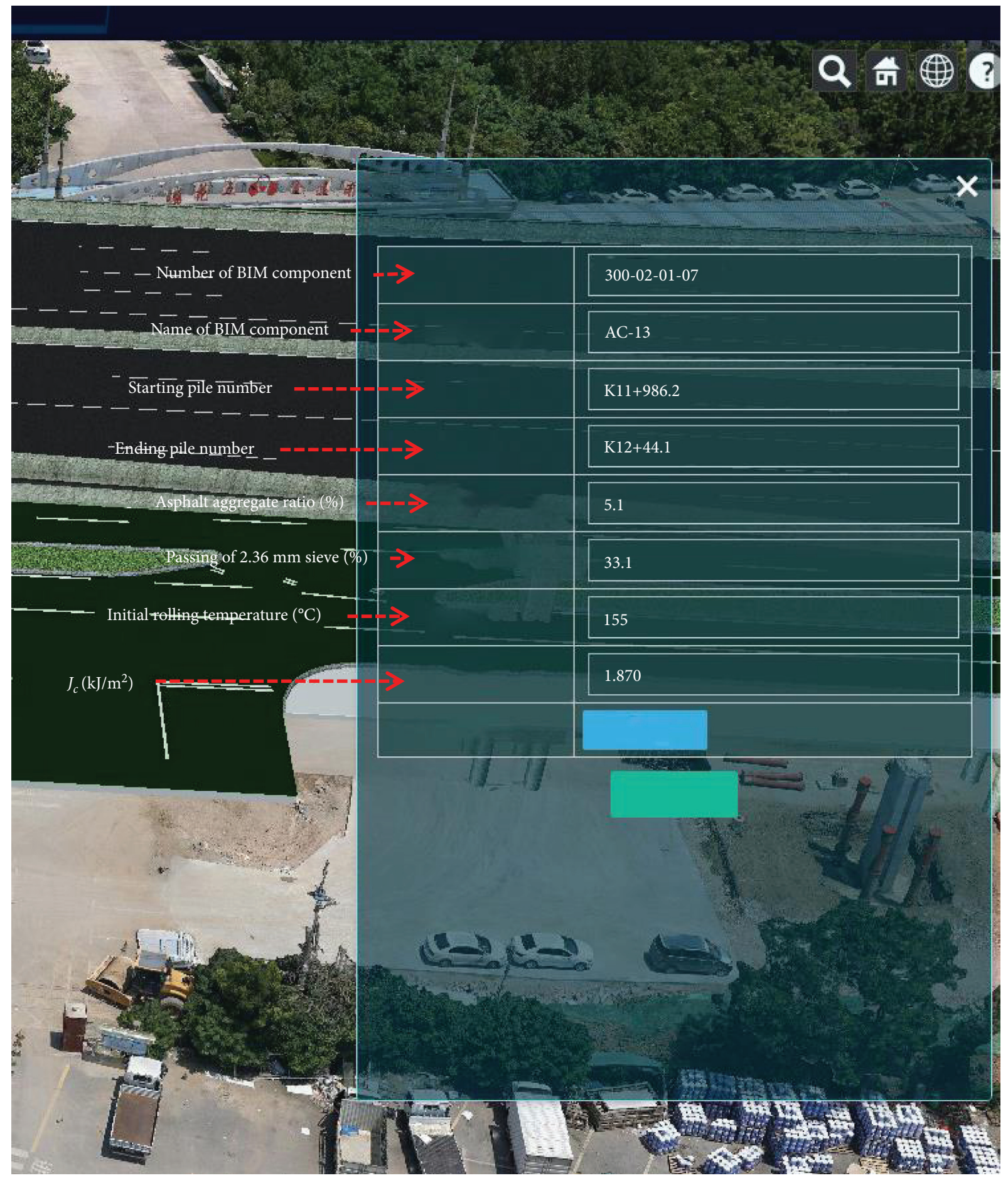

FIgURE 17: Display of construction information of a BIM component.

TABLE 19: Allowable ranges of fluctuation of key construction indices.

\begin{tabular}{lcccc}
\hline Item & $\begin{array}{c}\text { Asphalt-aggregate ratio } \\
(\%)\end{array}$ & $\begin{array}{c}\text { Passing of } 2.36 \mathrm{~mm} \text { sieve } \\
(\%)\end{array}$ & $\begin{array}{c}\text { Initial rolling temperature } \\
\left({ }^{\circ} \mathrm{C}\right)\end{array}$ & $J_{c}\left(\mathrm{~kJ} / \mathrm{m}^{2}\right)$ \\
\hline $\begin{array}{l}\text { Allowable range of } \\
\text { fluctuation }\end{array}$ & $5.0 \pm 0.3$ & $33.1 \pm 5$ & $\geq 160$ & $\geq 0.6$ \\
\hline
\end{tabular}




\section{Conclusions}

In this study, the influences of the fluctuations of the construction indices on the low-temperature performance of the asphalt mixture were estimated to determine the key construction indices. Based on the SCB test, the index of $J_{c}$ was used to characterize the low-temperature performance of asphalt mixtures. A new prediction model of critical strain energy release rate was developed to evaluate the construction quality of the asphalt layer. Five factors were considered for the lowtemperature performance of asphalt mixtures in this research. Furthermore, the BIM platform was built to monitor the construction quality of the asphalt layer. On the basis of the results and analysis, the following conclusions can be drawn:

(i) For the set factor levels, the order of importance of factors affecting the low-temperature performance of asphalt mixtures is asphalt-aggregate ratio, gradation, and molding temperature. Therefore, special attention should be paid to the fluctuation of the asphalt-stone ratio to ensure the low-temperature performance of the asphalt mixture in the asphalt mixture plant.

(ii) For the set factor levels, the $J_{c}$ value of the asphalt mixtures increases with the increase of the asphaltstone ratio. In the asphalt mixing plant, when the asphalt-stone ratio is less than the design value, the construction workers should pay more attention to this case.

(iii) The $J_{c}$ value of the asphalt mixtures decreases because of gradation coarsening due to segregation. The $J_{c}$ value of the asphalt mixtures increases as the gradation becoming finer due to segregation.

(iv) The $J_{c}$ value of the asphalt mixtures decreases with the increase in the degree of temperature segregation. And, the $J_{c}$ value of the asphalt mixtures drops about 6.3\%$23.6 \%$ for the set temperature segregation.

(v) For the single factor, the gradation coarsening due to segregation and the temperature segregation have a worse effect on the low-temperature performance of asphalt mixtures in the construction process of the asphalt layer.

(vi) Based on the results of the extraction test, the deviation between the predicted and measured values of critical strain energy release rate is small, which indicates that the prediction model of critical strain energy release rate has good applicability for AC-13.

(vii) The BIM platform was developed to monitor the real-time detection data from the construction process of the asphalt layer. The construction workers can grasp the construction quality of the asphalt layer in time based on this platform.

\section{Abbreviations \\ LTPP: Long-Term Pavement Performance \\ NCHRP: National Cooperative Highway Research Program}

BIM: $\quad$ Building Information Modeling

RFID: Radio Frequency Identification

SCB: $\quad$ Semicircular bend

SBS: $\quad$ Styrene-butadiene-styrene

AC-13: Asphalt concrete-13

OAR: Optimum asphalt-aggregate ratio

GPS- Global Positioning System-Real Time Kinematic

RTK:

OT: Orthogonal test

TGs: $\quad$ Test groups

3D: $\quad$ Three-dimensional

ETs: $\quad$ Extraction tests.

\section{Data Availability}

The data used to support the findings of this study are included within the article.

\section{Conflicts of Interest}

The authors declared that there are no conflicts of interest.

\section{Acknowledgments}

This study was supported by Shandong Provincial Natural Science Foundation (Grant No. ZR2020QE274), Key Research and Development Program of Shandong Province (Soft Science Project) (Grant No. 2020RKB01602), Science and Technology Plan of Shandong Transportation Department (Grant Nos. 2019B63 and 2020B93), National Natural Science Foundation of China (Grant No. 51878168), Open Research Fund of National Engineering Laboratory for Advanced Road Materials (Grant No. NLARM-ORF-201801), Provincial Natural Science Foundation of Anhui (Grant No. 1908085QE217), and Key Project of Natural Science Research of Anhui Provincial Department of Education (Grant Nos. KJ2018A0668 and KJ2020A1214).

\section{References}

[1] H. Zhang, M. Gong, Y. Huang, and M. Miljković, "Study of the high and low-temperature behavior of asphalt based on a performance grading system in Northeast China," Construction and Building Materials, vol. 254, pp. 1-10, 2020.

[2] H. Sun, Mechanical Analysis of Asphalt Pavement Low Temperature Cracking, Chang'an University, Xi'an, China, 2013.

[3] J.-R. Wu, F. Li, and Q.-Y. Ma, "Effect of polyester fiber on air voids and low-temperature crack resistance of permeable asphalt mixture," Advances in Civil Engineering, vol. 2020, Article ID 2381504, 12 pages, 2020.

[4] J. Shen, F. Li, and J. Chen, Analysis and Preventiue Techniques of Premature Damage of Asphalt Pavement in Expressway, China Communications Press, Beijing, China, 2004.

[5] A. Ebrahim Abu El-Maaty, A. Y. Akal, and S. El-Hamrawy, "Management of highway projects in Egypt through identifying factors influencing quality performance," Journal of Construction Engineering, vol. 2016, Article ID 4823630, 8 pages, 2016.

[6] Research Institute of Highway Ministry of Transport, Technical Specifications for Construction of Highway Asphalt 
Pavements, China Communications Press, Beijing, China, JTG F40-2004, 2004.

[7] North Carolina Department of Transportation, SUPERPAVE: Hot Mix Asphalt Quality Management System, North Carolina Department of Transportation, Raleigh, NC, USA, 2012.

[8] N. L. Li, X. P. Zhao, C. L. Zhang, Q. Y. Xiao, and H. H. Li, "Effect of aging on the low-temperature properties of asphalt mixture," Applied Mechanics and Materials, vol. 438-439, pp. 383-386, 2013.

[9] Q. Dong, X. Jiang, B. Huang, and S. H. Richards, "Analyzing influence factors of transverse cracking on LTPP resurfaced asphalt pavements through NB and ZINB models," Journal of Transportation Engineering, vol. 139, no. 9, pp. 889-895, 2013.

[10] Fugro Consultants INC and Arizona State University, $A$ Performance-Related Specification for Hot-Mixed Asphalt, NCHRP Rep. No. 704, Transportation Research Board, Washington, DC, USA, 2011.

[11] T. Wang, Research of Intelligent Technology of Quality Process Control of Asphalt Pavement, Hebei University of Technology, Tianjin, China, 2014.

[12] P. Zou, The Design and Implementation of Real-Time Detection System for Aggregate Gradation Based on Multi-Source Vision, Chang'an University, Xi'an, China, 2015.

[13] M. Moaveni, Advanced Image Analysis and Techniques for Degradation Characterization of Aggregates, University of Illinois at Urbana-Champaign, Champaign, IL, USA, 2015.

[14] I. S. Bessa, V. T. F. Castelo Branco, and J. B. Soares, "Evaluation of different digital image processing software for aggregates and hot mix asphalt characterizations," Construction and Building Materials, vol. 37, pp. 370-378, 2012.

[15] Y. Shi, Research on Informatization Control Technology of Asphalt Pavement Construction Quality, Southeast University, Nanjing, China, 2017.

[16] F. J. Blasco-López, F. J. Alejandre, V. Flores-Alés, and I. Cortés, "Plasterwork in the ambassadors Hall (salón de Embajadores) of the real alcázar of seville (Spain): graphic reconstruction of polychrome work by layer characterization," Construction and Building Materials, vol. 107, pp. 332-340, 2016.

[17] S. Lagüela, L. Díaz-Vilariño, J. Armesto, and P. Arias, "Nondestructive approach for the generation and thermal characterization of an as-built BIM," Construction and Building Materials, vol. 51, pp. 55-61, 2014.

[18] M. Lee and U.-K. Lee, "A framework for evaluating an integrated BIM ROI based on preventing rework in the construction phase," Journal of Civil Engineering and Management, vol. 26, no. 5, pp. 410-420, 2020.

[19] D.-G. Lee, J.-Y. Park, and S.-H. Song, "BIM-based construction information management framework for site information management," Advances in Civil Engineering, vol. 2018, Article ID 5249548, 14 pages, 2018.

[20] L. Ding and X. Xu, "Application of cloud storage on BIM lifecycle management," International Journal of Advanced Robotic Systems, vol. 11, no. 8, pp. 1-10, 2014.

[21] M. Das, J. C. P. Cheng, and K. H. Law, "An ontology-based web service framework for construction supply chain collaboration and management," Engineering, Construction and Architectural Management, vol. 22, no. 5, pp. 551-572, 2015.

[22] H.-M. Chen, K.-C. Chang, and T.-H. Lin, "A cloud-based system framework for performing online viewing, storage, and analysis on big data of massive BIMs," Automation in Construction, vol. 71, pp. 34-48, 2016.

[23] Y. C. Lin, H. Y. Lee, and I. T. Yang, "Developing as-built BIM model process management system for general contractors: a case study," Journal of Civil Engineering and Management, vol. 22, no. 5, pp. 608-621, 2016.

[24] J.-R. Lin, Z.-Z. Hu, J.-P. Zhang, and F.-Q. Yu, "A naturallanguage-based approach to intelligent data retrieval and representation for cloud BIM," Computer-Aided Civil and Infrastructure Engineering, vol. 31, no. 1, pp. 18-33, 2016.

[25] A. Sattineni and S. Azhar, "Techniques for tracking RFID tags in a BIM model," in Proceedings of the 27th International Symposium on Automation and Robotics in Construction, pp. 346-354, Bratislava, Slovania, 2010.

[26] A. J. L. Conde, J. García-Sanz-Calcedo, and A. M. R. Rodríguez, "Use of BIM with photogrammetry support in small construction projects. Case study for commercial franchises," Journal of Civil Engineering and Management, vol. 26, no. 6, pp. 513-523, 2020.

[27] Research Institute of Highway Ministry of Transport, Standard Test Methods of Bitumen and Bituminous Mixtures for Highway Engineering, China Communications Press, Beijing, China, JTG E20-2011, 2011.

[28] Research Institute of Highway Ministry of Transport, Test Methods of Aggregate for Highway Engineering, China Communications Press, Beijing, China, JTG E42-2005, 2005.

[29] L. Zhang, Research on Information-Based Control of Asphalt Pavement Compaction, Southeast University, Nanjing, China, 2014.

[30] K. A. Willoughby, J. S. Uhlmeyer, J. P. Mahoney, K. W. Anderson, and L. M. Pierce, "Construction-related variability in pavement mat density due to temperature differentials," Transportation Research Record: Journal of the Transportation Research Board, vol. 1849, no. 1, pp. 166-173, 2003.

[31] A. Shen, Y. Guo, F. Che, W. Yin, and Y. Li, "Influence of asphalt mixture segregation on long-term high temperature performance of asphalt pavement based on MMLS3 test," China Journal of Highway and Transport, vol. 25, no. 3, pp. 80-86, 2012.

[32] M. Stroup-Gardiner and E. R. Brown, Segregation in Hot-Mix Asphalt Pavements, Transportation Research Board, Washington, DC, USA, 2000.

[33] W. Wu, Z. Tu, Z. Zhu, Z. Zhang, and Y. Lin, "Effect of gradation segregation on mechanical properties of an asphalt mixture," Applied Sciences, vol. 9, no. 2, pp. 1-15, 2019.

[34] L. Garcia-Gil, R. Miró, and F. E. Pérez-Jiménez, "Evaluating the role of aggregate gradation on cracking performance of asphalt concrete for thin overlays," Applied Sciences, vol. 9, no. 4, pp. 1-13, 2019.

[35] J. Wu and P. Romero, "Performance testing of segregated hotmix asphalt samples to evaluate segregation models," Transportation Research Record, vol. 1907, pp. 118-127, 2005.

[36] Y. Zhao, Research on Construction Process Control of Asphalt Layer Based on BIM Technology, Southeast University, Nanjing, China, 2018.

[37] R. P. Leandro, K. L. Vasconcelos, and L. L. B. Bernucci, "Evaluation of the laboratory compaction method on the air voids and the mechanical behavior of hot mix asphalt," Construction and Building Materials, vol. 156, pp. 424-434, 2017.

[38] H. Li, Y. Gao, and W. Yu, "Compaction characteristics of hot mixed asphalt and number of roller passes," Journal of Southeast University (Natural Science Edition), vol. 41, no. 1, pp. 186-189, 2011.

[39] American Society for Testing and Materials, Standard Test Method for Evaluation of Asphalt Mixture Cracking Resistance Using the Semi-Circular Bend Test (SCB) at Intermediate 
Temperatures, American Society for Testing Materials, West Conshohocken, PA, USA, ASTM D8044-16, 2016.

[40] N. Xu, J. Zhao, F. Xie, Y. Wang, and X. Zhang, "Study on construction planning for bridge structure based on BIM technology," in Proceedings of the 2020 International Conference on Intelligent Transportation, Big Data \& Smart City (ICITBS), pp. 219-223, IEEE, Vientiane, Laos, 2020.

[41] F. Rodrigues, J. Teixeira, R. Matos, and H. Rodrigues, "Development of a web application for historical building management through BIM technology," Advances in Civil Engineering, vol. 2019, Article ID 9872736, 15 pages, 2019.

[42] T. Wang, F. Xiao, S. Amirkhanian, W. Huang, and M. Zheng, "A review on low temperature performances of rubberized asphalt materials," Construction and Building Materials, vol. 145, pp. 483-505, 2017.

[43] M. Juszczyk, K. Zima, and W. Lelek, "Forecasting of sports fields construction costs aided by ensembles of neural networks," Journal of Civil Engineering and Management, vol. 25, no. 7, pp. 715-729, 2019.

[44] L. N. Mohammad, M. Kim, and H. Challa, Development of Performance-Based Specifications for Louisiana Asphalt Mixtures, Louisiana State University, Baton Rouge, LA, USA, FHWA/LA.14/558, 2016.

[45] R. Cao, Y. Zhao, Y. Gao, X. Huang, and L. Zhang, "Effects of flow rates and layer thicknesses for aggregate conveying process on the prediction accuracy of aggregate gradation by image segmentation based on machine vision," Construction and Building Materials, vol. 222, pp. 566-578, 2019.

[46] American Association of State Highway and Transportation Officials, Standard Specification for Superpave Volumetric Mix Design, American Association of State Highway and Transportation Officials, Washington, DC, USA, AASHTO M 32317, 2017. 